Review

\title{
The Vitamin Nicotinamide: Translating Nutrition into Clinical Care
}

\author{
Kenneth Maiese ${ }^{1,2,3,4,5, *}$, Zhao Zhong Chong ${ }^{1}$, Jinling Hou ${ }^{1}$ and Yan Chen Shang ${ }^{1}$
}

1 Division of Cellular and Molecular Cerebral Ischemia, Wayne State University School of Medicine, Detroit, Michigan 48201, USA

2 Departments of Neurology and Anatomy \& Cell Biology, Wayne State University School of Medicine, Detroit, Michigan 48201, USA

3 Barbara Ann Karmanos Cancer Institute, Wayne State University School of Medicine, Detroit, Michigan 48201, USA

4 Center for Molecular Medicine and Genetics, Wayne State University School of Medicine, Detroit, Michigan 48201, USA

5 Institute of Environmental Health Sciences, Wayne State University School of Medicine, Detroit, Michigan 48201, USA

* Author to whom correspondence should be addressed; E-mails: kmaiese@med.wayne.edu or aa2088@wayne.edu; Fax: +1-313-966-0486.

Received: 17 August 2009; in revised form: 8 September 2009 / Accepted: 8 September 2009 / Published: 9 September 2009

\begin{abstract}
Nicotinamide, the amide form of vitamin $\mathrm{B}_{3}$ (niacin), is changed to its mononucleotide compound with the enzyme nicotinic acide/nicotinamide adenylyltransferase, and participates in the cellular energy metabolism that directly impacts normal physiology. However, nicotinamide also influences oxidative stress and modulates multiple pathways tied to both cellular survival and death. During disorders that include immune system dysfunction, diabetes, and aging-related diseases, nicotinamide is a robust cytoprotectant that blocks cellular inflammatory cell activation, early apoptotic phosphatidylserine exposure, and late nuclear DNA degradation. Nicotinamide relies upon unique cellular pathways that involve forkhead transcription factors, sirtuins, protein kinase B (Akt), Bad, caspases, and poly (ADP-ribose) polymerase that may offer a fine line with determining cellular longevity, cell survival, and unwanted cancer progression. If one is cognizant of the these considerations, it becomes evident that nicotinamide holds great potential for multiple disease entities, but the development of new therapeutic
\end{abstract}


strategies rests heavily upon the elucidation of the novel cellular pathways that nicotinamide closely governs.

Keywords: Alzheimer's disease; diabetes; erythropoietin; forkhead transcription factors; Wnt

\section{Introduction}

Nicotinamide (Figure 1) is the amide form of vitamin $\mathrm{B}_{3}$ (niacin) and is obtained through synthesis in the body or as a dietary source and supplement [1]. Nicotinic acid is the other form of the watersoluble vitamin $\mathrm{B}_{3}$ (Figure 1). Although also present from animal sources, the principal form of niacin in dietary plant sources is nicotinic acid that is rapidly absorbed through the gastrointestinal epithelium [2]. Nicotinamide is subsequently generated through the conversion of nicotinic acid in the liver or through the hydrolysis of $\mathrm{NAD}^{+}$. Once nicotinamide is obtained in the body, it functions as the precursor for the coenzyme $\beta$-nicotinamide adenine dinucleotide $\left(\mathrm{NAD}^{+}\right)[3,4]$ and also is essential for the synthesis of nicotinamide adenine dinucleotide phosphate $\left(\mathrm{NADP}^{+}\right)$[5]. Initially, nicotinamide is changed to its mononucleotide form (NMN) with the enzyme nicotinic acid/nicotinamide adenylyltransferase yielding the dinucleotides $\mathrm{NAAD}^{+}$and $\mathrm{NAD}^{+} . \mathrm{NAAD}^{+}$also yields $\mathrm{NAD}^{+}$through $\mathrm{NAD}^{+}$synthase [6] or $\mathrm{NAD}^{+}$can be synthesized through nicotinamide riboside kinase that phosphorylates nicotinamide riboside to NMN [7,8]. These cellular pathways are essential for energy metabolism and may directly impact normal physiology, as well as disease progression [9-12].

In deficiency states, lack of nicotinamide can lead to fatigue, loss of appetite, pigmented rashes of the skin, and oral ulcerations. More severe states of deficiency lead to pellagra that is characterized by cutaneous rashes, oral ulcerations, gastrointestinal difficulties, and cognitive loss. Pellagra can occur during low nicotinamide conditions or due to the inability to absorb nicotinamide. For example, inability to absorb tryptophan that causes Hartnup's disease, isoniazid treatment, or carcinoid syndrome also can be associated with pellagra. Excessive alcohol consumption that is associated with poor dietary intake also can lead to severe nicotinamide loss and insufficient gastrointestinal absorption.

Figure 1. Chemical structures of nicotinamide and nicotinic acid.

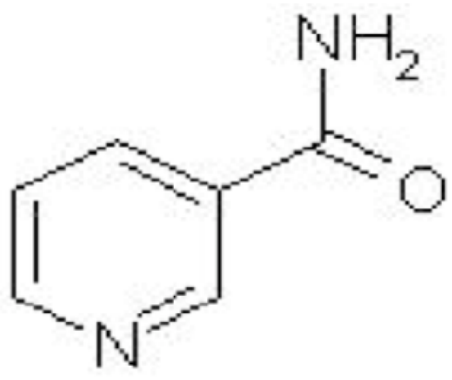

Nicotinamide

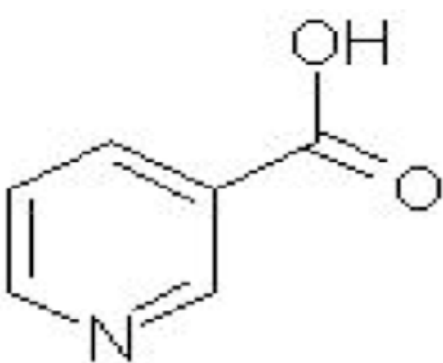

Nicotinic acid 


\section{Nicotinamide, Oxidative Stress, and Cellular Survival}

Ultimate cellular survival can be determined by a number of factors, but the process of apoptosis can represent one of the critical pathways for a number of disease entities. Apoptosis can contribute to disorders such as diabetes [13-16], tissue ischemia [17-20], bone fatigue [21], Alzheimer's disease [22-32], neurodegenerative disorders [33-36], plasticity associated with ischemic preconditioning [37], aging-related diseases [38-40], and toxic conditions during development [41,42]. The pathology with these disorders can be linked to mitochondrial dysfunction [43-46], especially during metabolic disorders [47] and Alzheimer's disease [48], that ultimately can lead to cell death in a variety of cells such as neurons, endothelial cells (ECs), cardiomyocytes, and smooth muscle cells [32,49-53].

At the cellular level, apoptosis consists of both the early exposure of membrane phosphatidylserine (PS) residues and the subsequent destruction of genomic DNA [54,55]. Externalization of membrane PS residues can occur first during cellular apoptosis [56,57]. Apoptotic membrane PS exposure occurs in neurons, vascular cells, and inflammatory microglia during reduced oxygen exposure [58-62], $\beta$ amyloid (A $\beta$ ) exposure [26,63], nitric oxide exposure [64-68], and during the administration of agents that induce the production of reactive oxygen species (ROS), such as 6-hydroxydopamine [69]. Membrane PS externalization also occurs on platelets and has been associated with clot formation in the vascular system [70]. Furthermore, membrane PS exposure can become a signal for the phagocytosis of cells $[59,71,72]$. The loss of membrane phospholipid asymmetry leads to the exposure of membrane PS residues on the cell surface and assists microglia to target cells for phagocytosis [4,52,73-75]. In conjunction with PS externalization, increased expression of the phosphatidylserine receptor (PSR) on microglia occurs to facilitate activation of these cells [76,77] since blockade of PSR function prevents the activation of microglia [74,78].

Usually following membrane PS exposure [79], the cleavage of genomic DNA into fragments occurs $[35,61,80]$ as a later event during apoptotic injury [52,80-82]. There are a number of enzymes that degrade DNA. These include the acidic, cation independent endonuclease (DNase II), cyclophilins, and the $97 \mathrm{kDa}$ magnesium - dependent endonuclease [83,84]. In addition, three separate endonuclease activities have been found in neurons that include a constitutive acidic cationindependent endonuclease, a constitutive calcium/magnesium-dependent endonuclease, and an inducible magnesium dependent endonuclease [85,86].

One of the inciting factors that can lead to apoptotic cell injury is oxidative stress. Oxidative stress plays a critical role in the pathology of numerous processes and disorders throughout the body that can include metabolic disorders [47,87-95], ocular disease [96], environmental influences such as with tobacco exposure [97,98], cognitive impairment [99-102], ischemic injury [103,-105], epilepsy [106,107], nutrition [108], cardiopulmonary and hepatic disease [109-111], degenerative disorders and psychiatric disorders [112-114], infertility [115-117], excitotoxicity [118-120], and drug toxicity [121123]. Early work with oxidative stress examined the rate of oxygen consumption in organisms and proposed that increased exposure to oxygen through a high metabolic rate could lead to a shortened life span [124]. Other work demonstrated that increased metabolic rates could be detrimental to animals in an elevated oxygen environment [125].

Recent studies have expanded these observations to show that ROS and mitochondrial DNA mutations have become associated with multiple processes to include cellular injury, aging 
mechanisms, and accumulated toxicity for an organism [126]. It is the release of ROS that leads to oxidative stress. ROS include superoxide free radicals, hydrogen peroxide, singlet oxygen, nitric oxide (NO), and peroxynitrite $[34,83,127]$ that if expressed at increased concentrations can lead to cellular injury and demise through oxidative stress [59,128,129]. Most ROS occur at low levels and are scavenged by endogenous antioxidant systems that include superoxide dismutase (SOD), glutathione peroxidase, catalase, and small molecule substances such as vitamins $\mathrm{C}, \mathrm{D}, \mathrm{E}$, and $\mathrm{K}$ [76,107,114,130,131]. Yet, one vitamin in particular, namely nicotinamide may be considered to stand-alone among antioxidants since nicotinamide influences multiple pathways tied to both cellular survival and cellular death.

In several scenarios, nicotinamide is a robust cytoprotectant that addresses both early membrane PS externalization and later genomic DNA degradation [3,4,34,76,132] during oxidative stress in a way that is different from other vitamin entities. Administration of nicotinamide during anoxia, oxygenglucose deprivation, and free radical exposure can prevent exposure of membrane PS residues to block inflammatory cell activation [3,133-135] and inhibit later genomic DNA destruction [134-136] (Figure 2). In addition, nicotinamide prevents membrane PS exposure in vascular cells $[4,134]$ that can reduce risk for cardiovascular disorders, since membrane PS residue externalization in vascular cells can lead to increased propensity for hypercoagulation [137] and cellular inflammation [138,139].

Figure 2. Nicotinamide prevents nuclear DNA fragmentation during oxidative stress with oxygen-glucose (OGD) deprivation. Representative images illustrate that nicotinamide (12.5 $\mathrm{mM})$ with one hour pretreatment prior to OGD significantly blocked neuronal genomic DNA degradation assessed by terminal deoxynucleotidyl transferase nick end labeling (TUNEL) assay 24 hours after OGD.

Control

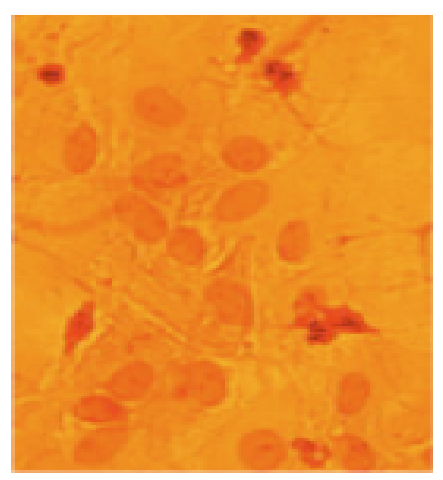

OGD

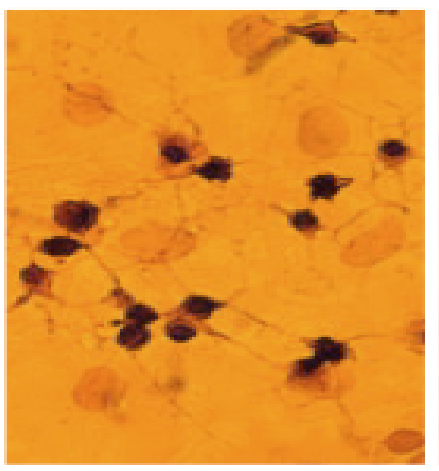

NIC/OGD

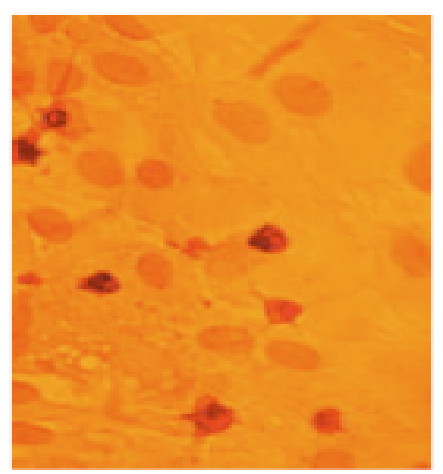

In several instances, nicotinamide also may reverse a previously sustained insult [4,132-135,140]. Post-treatment strategies with nicotinamide that can follow apoptotic injury in "real-time" show that cellular injury can be reversed. Nicotinamide can reverse an initial progression of membrane PS inversion and prevent PS exposure over a twenty-four hour period [4,132,135,141]. These results suggest that apoptosis prior to reaching genomic DNA degradation is dynamic and reversible in nature $[4,132,135,141]$. Yet, in not all cases may nicotinamide be effective to prevent subsequent DNA degradation [76]. During periods of acidosis-induced cellular toxicity [142], mitochondrial failure can ensue [143]. In addition, ROS can result in the disturbance of intracellular $\mathrm{pH}$ that leads to 
endonuclease activity and DNA injury during apoptosis [85,86,144]. In events that involve decreased $\mathrm{pH}$, nicotinamide cannot prevent cellular injury during intracellular acidification [135]. For example, exposure to ROS leads to a biphasic response for $\mathrm{pH}_{\mathrm{i}}$. Treatment with nicotinamide $(12.5 \mathrm{mM})$ alone does not alter neuronal $\mathrm{pH}_{\mathrm{i}}$. In addition, pretreatment with nicotinamide $(12.5 \mathrm{mM})$, a neuroprotective concentration, 1 hour prior to ROS exposure does not significantly prevent the rapid acidification in neuronal cultures (pH $6.98 \pm 0.06$ ) during ROS exposure [135].

Nicotinamide is considered to have protean endocrine effects $[145,146]$, the ability to scavenge ROS, and offers cellular protection for both neuronal $[140,147,148]$ and vascular cells $[3,4,34,76]$. In neuronal cell populations, nicotinamide protects against free radical injury [135], anoxia [132], excitotoxicity [149], homocysteine toxicity [150], ethanol-induced neuronal injury [151], and oxygenglucose deprivation [140,152]. Nicotinamide prevents oxidant-induced apoptotic neuronal injury usually in a specific concentration range. Administration of nicotinamide in a range of 5.0-25.0 mmol/L significantly protect neurons during oxidative stress injuries (Figure 3). This concentration range is similar to other injury paradigms in both animal models [136] and in cell culture models $[4,134,135]$. In cortical neurons, nicotinamide antagonizes cell injury during ROS generating toxins such as tertiary butylhydroperoxide [153]. Nicotinamide also can protect both rod and cone photoreceptor cells against $\mathrm{N}$-methyl-N-nitrosourea toxicity $[136,154]$ as well as against glycation end products in all layers of the retina [155]. In animal studies, nicotinamide improves cognitive function, cell survival, and reduces edema following cortical trauma [156-161], limits axonal degeneration [162], reduces cerebral ischemia [163-165] sometimes more effectively in models that were absent of comorbidities [166], prevents spinal cord injury [167,168], and lessens disability in models of Parkinson's disease in specific concentrations [169-171].

Figure 3. Nicotinamide leads to increased cell survival in a specific concentration range. Increasing concentrations of nicotinamide (1-100 mmol/L) were administered one hour prior to oxygen-glucose (OGD) deprivation to primary hippocampal neurons and cell injury was assessed 24 hours later with the trypan blue dye exclusion assay. Optimal cellular protection for nicotinamide occurs in the concentration range of $5.0-25.0 \mathrm{mmol} / \mathrm{L}$.

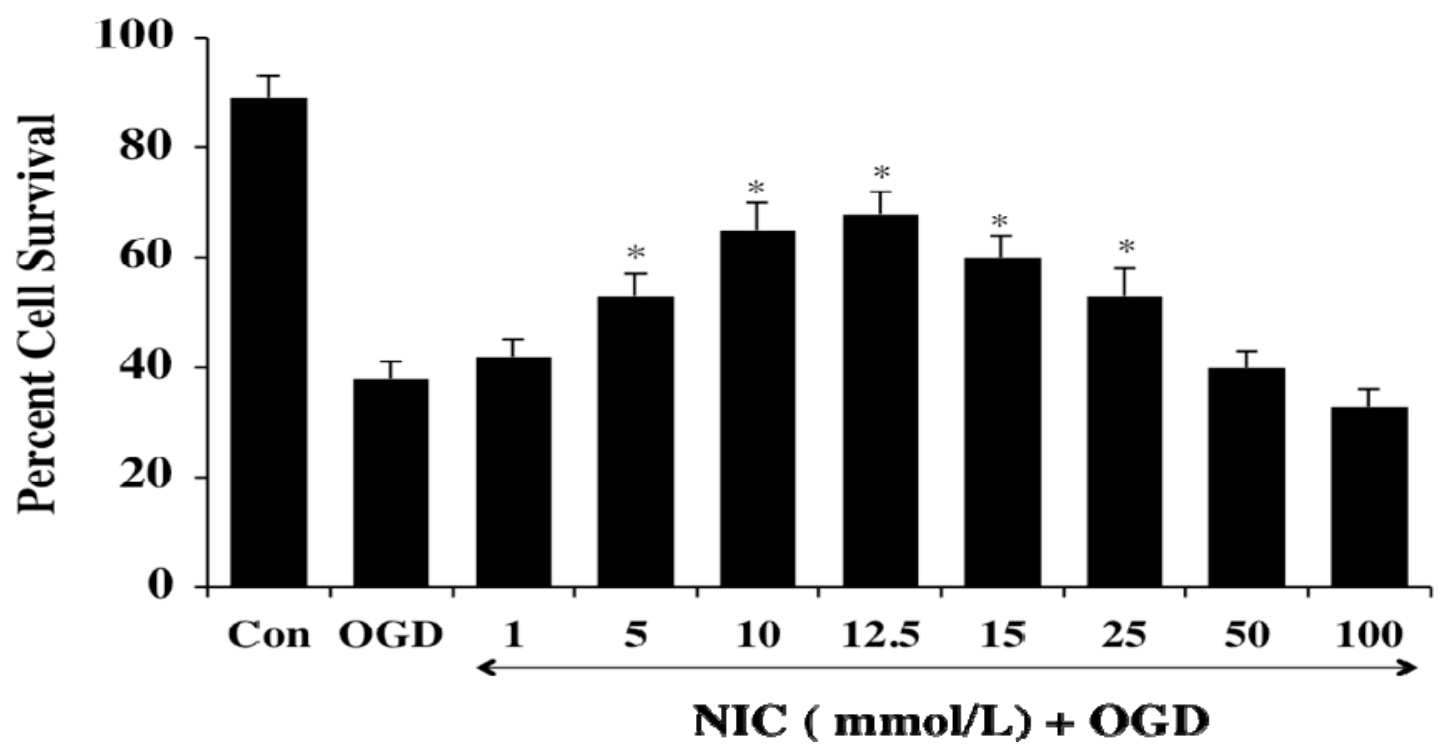


In addition to the observed neuroprotection with nicotinamide [140,147,148], the agent is also involved in the maintenance of vascular integrity [3,4,76]. For example, nicotinamide can protect the function of the blood brain barrier [156,157], influence arteriolar dilatation and blood flow [172], increase skin vascular permeability [173], potentially lead to decreased atherosclerotic plaque through inhibition of poly(ADP-ribose) polymerase [174], and promote platelet production through megakaryocyte maturation [175]. Nicotinamide also can maintain EC viability during ROS exposure [132-135,176]. Nicotinamide is believed to be responsible for the preservation of cerebral [177] and endocardial [178,179] ECs during models of oxidative stress [178,179]. However, recent reports suggest that pathways of nicotinamide also may have unclear vascular effects and may either prevent or contribute to atherosclerotic plaques over a three to six month progression [180]. It is possible that these events may occur during acidosis-induced cellular toxicity. During periods such as ischemia and oxidative stress, acidosis-induced cellular toxicity may ensue [142] and lead to subsequent mitochondrial failure [143]. Free radicals [86,144,181] can result in the disturbance of intracellular $\mathrm{pH}$. In addition, modulation of intracellular $\mathrm{pH}$ is physiologically relevant for endonuclease activities during apoptosis $[85,86,144]$. As previously noted, nicotinamide cannot prevent cellular injury during intracellular acidification paradigms [135].

\section{Nicotinamide and Inflammatory Cell Modulation}

Closely tied to cellular survival and the ultimate disposal of non-functional cells is the activation of inflammatory cells [117,182]. As an example, when one considers disorders such as dementia [183] and inflammatory microglial cells of the brain, these cells can result in the phagocytic removal of both neurons and vascular cells $[49,52,71]$. During periods of inflammatory cell activation, microglia rely upon cytoprotective pathways [50,72] to proliferate and remove cells that are no longer functional [75,184]. Microglia can be beneficial in many ways to function as immune surveillance for toxic products [185], such as $\beta$-amyloid [186], block foreign microorganisms from entering the central nervous system and to allow for the repair of tissues composed of neuronal and vascular cells [50,187]. However, microglia have another side that may be detrimental to an organism. They can generate ROS [188,189], may worsen events with oxidative stress injury [190], and activate cytokines that in some circumstances may initially lead to cell proliferation [191], but later can lead to the demise of cells [192-194].

A number of cytoprotective agents rely upon the modulation of the immune system to control cellular survival. In particular, erythropoietin (EPO) is a prime example of a cytoprotective agent that is strongly associated with immune system pathways. Although EPO is approved by the Food and Drug Administration for the treatment of anemia and can have unwanted effects [127,195-197], it has recently been shown to significantly affect cell survival throughout the body [127,139,198,199], especially in regards to cellular proliferation [200-203]. EPO can reduce cytokine gene expression in endothelial cells exposed to tumor necrosis factor [204], prevent ulcer progression in cases of scleroderma [205], modulate inflammation during experimental autoimmune encephalomyelitis [206], reduce inflammation in murine arthritis models [207], and block primary microglial activation and proliferation during oxidative stress $[25,78]$ to prevent phagocytosis of injured cells through pathways that involve cellular membrane PS exposure, protein kinase B (Akt) [49], and the regulation of 
caspases $[78,208,209]$. EPO can directly inhibit several pro-inflammatory cytokines, such as IL-6, tumor necrosis factor (TNF)- $\alpha$, and monocyte chemoattractant protein 1 [199,210], and reduce leukocyte inflammation [211]. EPO also may foster the preservation of microglial cells for neuronal and vascular restructuring by preventing apoptotic injury in microglia [72,212].

EPO, although concentration dependent [78,138,208,213], can reduce cell injury during multiple events such as hyperoxia [214,215], hypoxia [78,138,216-220], parasitic infections [221-223], ROS exposure [64,208,224], ischemic/reperfusion insults [225-229], endotoxin shock [230,231], pulmonary disease [232-234], epileptic activity [235-237], elevated glucose exposure [238-240], excitotoxicity [224,241,242], mitochondrial failure [64,216,243], amyloid toxicity [25,244,245], cardiac and vascular injury [246-252], trauma [253-256], retinal disease [257], and renal failure [258-260].

Similar to agents such as EPO, nicotinamide can regulate cellular inflammation. Nicotinamide blocks pro-inflammatory cytokines, such as interleukin-1ß, interleukin-6, interleukin-8, tissue factor, and TNF- $\alpha$ [261-264] as well as transforming growth factor (TGF) $\beta 2$, IL-1 $\beta$, TNF- $\alpha$, and macrophage chemotactic protein-1 in hepatic cells [265]. Nicotinamide affects major histocompatibility complexes [266], inhibits intracellular adhesion molecule expression [267], and modulates TNF in vascular cells [266] that may account for the ability of nicotinamide to reduce demyelination in models of multiple sclerosis [268]. Nicotinamide also may control inflammatory mechanisms that lead to arthritis, such as the inhibition of collagen II expression [269] as well as contact hypersensitivity reactions [270]. Yet, the role of nicotinamide during inflammation is not entirely clear, since some investigations that examined the ability of oral nicotinamide administration to reduce cytokine production following endotoxin challenge in healthy volunteers did not demonstrate a significant effect upon serum cytokine levels [271].

\section{Nicotinamide, Metabolic Disease, and Energy Management}

Nicotinamide may have an important role during cellular energy management and metabolic disorders such as diabetes mellitus (DM). DM affects both young and older individuals [15,16]. Almost 20 million individuals in the United States and more than 165 million individuals worldwide suffer from DM with increasing incidence [272]. By the year 2030, it is predicted that more than 360 million individuals will be afflicted with DM and its debilitating conditions. Type 2 DM represents at least 80 percent of all diabetics and is dramatically increasing in incidence as a result of changes in human behavior and increased body mass index [15,91]. Type 1 insulin-dependent DM is present in 5-10 percent of all diabetics and affects three million individuals in the United States alone, but is increasing at a rate of $4 \%$, especially in adolescent minority groups [15,91]. Additional concerns are evident with the knowledge that a significant portion of the population has undiagnosed diabetes and impaired glucose tolerance, illustrating the need for improved early diagnosis [273].

Patients with DM can develop significant neurodegenerative [34,39,91], affective disorders [274], cognitive loss [275], and cardiovascular disease [91,276]. Interestingly, the development of insulin resistance and the complications of DM can be the result of cellular oxidative stress [15,91]. Hyperglycemia can lead to increased production of ROS in endothelial cells, liver cells, and pancreatic $\beta$-cells $[15,16,91]$ and lead to apoptotic injury [55,239]. Recent clinical correlates support these experimental studies to show that elevated levels of ceruloplasmin are suggestive of increased ROS 
$[15,16,91]$. Furthermore, acute glucose swings in addition to chronic hyperglycemia can trigger oxidative stress mechanisms, illustrating the importance for therapeutic interventions during acute and sustained hyperglycemic episodes [15,91].

In regards to nicotinamide and its role during metabolic disorders, nicotinamide appears to have a close relationship with metabolic pathways that may lead to clinical cognitive effects [277]. Treatment with nicotinamide can maintain approximately normal fasting blood glucose with streptozotocininduced DM in animal models [278,279]. Nicotinamide also can reduce peripheral nerve injury during elevated glucose [280], lead to the remission of type 1 DM in mice with acetyl-1-carnitine [281], and can inhibit oxidative stress pathways that lead to apoptosis [10,133,134,151,282]. Nicotinamide also

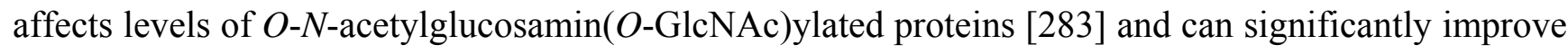
glucose utilization, prevent excessive lactate production and improve electrophysiologic capacity in ischemic animal models [284]. Oral nicotinamide administration $\left(1,200 \mathrm{mg} / \mathrm{m}^{2} /\right.$ day $)$ protects $\beta$-cell function and prevents clinical disease in islet-cell antibody-positive first-degree relatives of type-1 DM [285]. In addition, nicotinamide administration $(25 \mathrm{mg} / \mathrm{kg})$ in patients with recent onset type-1 DM combined with intensive insulin therapy for up to two years after diagnosis significantly reduced $\mathrm{HbA}_{1 \mathrm{c}}$ levels [286]. Potentially relevant to diabetic patients with renal failure, nicotinamide also has been shown to reduce intestinal absorption of phosphate and prevent the development of hyperphosphatemia and progressive renal dysfunction [287]. However, it is important to note that prolonged exposure to nicotinamide in some studies may lead to impaired $\beta$-cell function and reduction in cell growth [288,289]. Furthermore, nicotinamide also may inhibit P450 and hepatic metabolism [290] and play a role in the progression of other disorders such as Parkinson's disease [171].

Nicotinamide through $\mathrm{NAD}^{+}$has a critical physiological role in cellular metabolism and can be directly utilized by cells to synthesize $\mathrm{NAD}^{+}[4,34,76]$. Nicotinamide also participates in energy metabolism through the tricarboxylic acid cycle by utilizing $\mathrm{NAD}^{+}$in the mitochondrial respiratory electron transport chain for the production of ATP, DNA synthesis, and DNA repair [291-293]. Furthermore, nicotinamide can significantly increase $\mathrm{NAD}^{+}$levels in vulnerable regions of the ischemic brain, suggesting that nicotinamide may offer cytoprotection of injured tissue through the maintenance of $\mathrm{NAD}^{+}$levels [177]. During axonal degeneration, nicotinamide also may promote neuroprotection through $\mathrm{NAD}^{+}$-dependent mechanisms [162].

The preservation of cellular energy reserves is dependent upon the maintenance of mitochondrial integrity during DM [294]. ROS exposure can result in the opening of the mitochondrial membrane permeability transition pore $[52,135,208,295]$, reduce mitochondrial $\mathrm{NAD}^{+}$stores, and result in apoptotic cell injury [83]. Free fatty acids can lead to ROS release and contribute to mitochondrial DNA damage and impaired pancreatic $\beta$-cell function [296]. In patients with type 2 DM, skeletal muscle mitochondria have been described to be smaller than those in control subjects [297]. In addition, a decrease in the levels of mitochondrial proteins and mitochondrial DNA in adipocytes has been correlated with the development of type 2 DM [298]. Insulin resistance in the elderly also has been associated with elevation in fat accumulation and reduction in mitochondrial oxidative and phosphorylation activity [299]. An association also exists with insulin resistance and the impairment of intramyocellular fatty acid metabolism in young insulin-resistance offspring of parents with type 2 DM [300]. 
Nicotinamide appears to function directly at the level of mitochondrial membrane pore formation $[4,134,141]$ to prevent the release of cytochrome c [133] (Figure 4). Pretreatment of cells with either nicotinamide alone or in combination with the mitochondrial permeability transition pore inhibitor cyclosporin A prior to an injury paradigm can equally prevent mitochondrial membrane depolarization [301,302]. Nicotinamide can prevent the chemical induction of mitochondrial membrane depolarization during exposure to either tert-butylhydroperoxide or atractyloside [140]. There are additional pathways that nicotinamide may use to maintain cellular metabolic homeostasis through the maintenance of mitochondrial membrane potential [134,135]. Nicotinamide can phosphorylate Bad [133] to prevent mitochondrial membrane depolarization and subsequent cytochrome c release. In addition, nicotinamide may inhibit the assembly of the mitochondrial permeability transition pore complex similar to the action of cyclosporin A [303] as well as stabilize cellular energy metabolism since the maintenance of mitochondrial membrane potential is an ATP facilitated process [304].

Figure 4. Nicotinamide prevents mitochondrial membrane depolarization during oxidative stress. Oxygen-glucose deprivation (OGD) produces a significant decrease in the red/green fluorescence intensity ratio of mitochondria using a cationic membrane potential indicator JC-1 within six hours when compared with untreated control cultures, demonstrating that OGD results in mitochondrial membrane depolarization. Pretreatment with nicotinamide one hour prior to OGD significantly increases the red/green fluorescence intensity of mitochondria, indicating that membrane potential is restored by nicotinamide.

Control

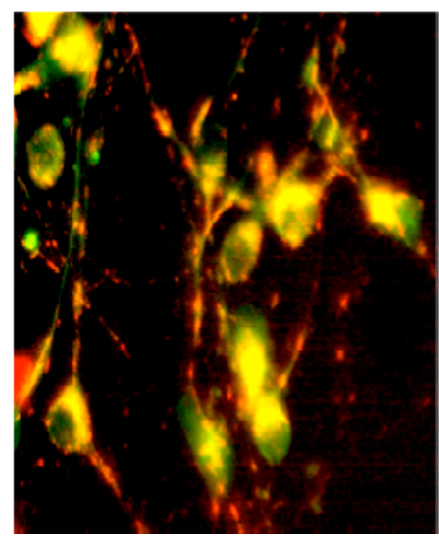

OGD

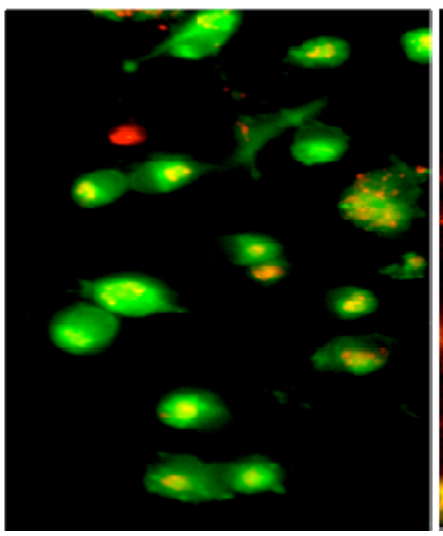

NIC/OGD

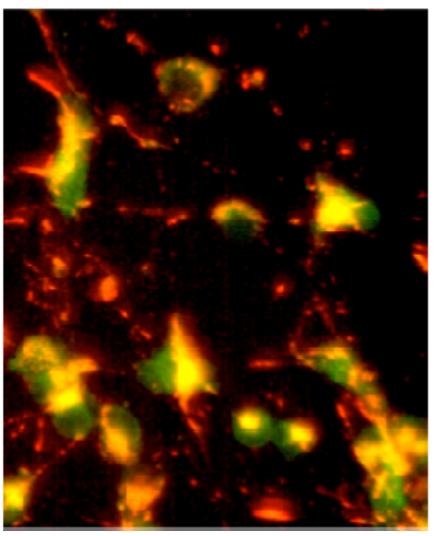

\section{Novel Intracellular Signaling for Nicotinamide}

\subsection{Forkhead transcription factors}

Forkhead transcription factors of the "O" class (FoxOs) have recently been shown to mediate some of the biological effects of nicotinamide $[305,306]$. FoxO proteins either inhibit or activate target gene expression by binding bind to DNA through the forkhead domain that relies upon fourteen proteinDNA contacts [305,307-310]. According to X-ray crystallography [311] or nuclear magnetic resonance imaging [312], the forkhead domain is described as a "winged helix" as a result of a butterfly-like appearance. Members of this family that include FoxO1, FoxO3, FoxO4, and FoxO6 are found throughout the body and are expressed in tissues of the reproductive system of males and 
females, skeletal muscle, the cardiovascular system, lung, liver, pancreas, spleen, thymus, and the nervous system [117,309,310,313]. In addition, FoxOs govern a number of processes that involve cellular proliferation, degeneration, longevity, and neoplastic growth that may have associations with several novel pathways including wingless [26,55,77,184,314-320]. Other members of the forkhead family also rely upon wingless signaling that involve regulated as well as unchecked cellular growth $[39,77,116,321,322]$.

Control of FoxO3a is a viable therapeutic target for agents such as metabotropic glutamate receptors [323], neurotrophins [324], cancer [117,309,325], and cytokines such as EPO [248] to increase cell survival. Recent work illustrates that FoxO3a may control early activation and subsequent apoptotic injury in microglia during $A \beta$ exposure through caspase 3 [63]. Since $A \beta$ exposure can facilitate the cellular trafficking of FoxO3a from the cytoplasm to the cell nucleus to potentially lead to apoptosis [63], one program in particular that may be vital for apoptotic injury appears to involve the activation of caspase 3 . A $\beta$ exposure leads to a rapid and significant increases in caspase 3 activity with six hours following $A \beta$ administration, but that this induction of caspase 3 activity by $A \beta$ requires FoxO3a, since loss of FoxO3a through gene silencing prevents the induction of caspase 3 activity by $\mathrm{A} \beta$.

Nicotinamide has been shown to inhibit FoxO protein activity [140] and may be protective through two separate mechanisms of post-translational modification of FoxO3a [39,116,117,310,326] (Figure 5). Nicotinamide not only can maintain phosphorylation of FoxO3a and inhibit its activity to potentially block caspase 3 activity [140], but also can preserve the integrity of the FoxO3a protein to block FoxO3a proteolysis that can yield pro-apoptotic amino-terminal fragments [140]. During oxidative stress, an initial inhibitory phosphorylation of FoxO3a at the regulatory phosphorylation sites $\left(\mathrm{Thr}^{32}\right.$ and $\mathrm{Ser}^{253}$ ) occurs [140,196]. However, loss of phosphorylated FoxO3a expression appears to subsequently result over twelve hours, possibly by caspase degradation, which potentially can enhance the vulnerability of neurons to apoptotic injury [140]. The loss of both FoxO3a phosphorylation and the integrity of this transcription factor may then lead to apoptosis. FoxO3a proteolysis occurs during cell injury yielding an amino-terminal $(\mathrm{Nt})$ fragment that can become biologically active and lead to cellular injury [327]. Nicotinamide, through the phosphorylation of FoxO3a at regulatory sites that possess high affinity for protein kinase B (Akt) can prevent apoptotic cell injury [140]. In addition, modulation of caspase 3 activity by nicotinamide appears to be tied to a unique regulatory mechanism that blocks the proteolytic degradation of phosphorylated FoxO3a by caspase 3. Since FoxO3a has been shown to be a substrate for caspase 3-like proteases at the consensus sequence $\mathrm{DELD}^{304} \mathrm{~A}$ [327], blockade of caspase 3 activity prevents the destruction of phosphorylated FoxO3a during oxidative stress [140], suggesting that nicotinamide maintains a regulatory loop through the modulation of caspase 3 and the preservation of phosphorylated FoxO3a integrity.

FoxO proteins also have been associated with cell longevity and aging as shown by early studies linking DAF-16 in Caenorhabditis elegans to increased longevity as well as the association with sirtuins [117,306,328-330]. Yet, the relationship among nicotinamide, FoxO transcription factors, and proteins that increased cellular lifespan is not entirely clear. For example, the sirtuin Sirt1 is a NAD ${ }^{+}$ dependent deacetylase and the mammalian ortholog of the silent information regulator 2 (Sir2) protein associated with increased lifespan in yeast. Some studies suggest that stimulation of Sirt1 during starvation is dependent upon FoxO3a activity as well as p53 [331]. In addition, during exercise, an up- 
regulation of FoxO3a and Sirt1 activity is observed in the heart [332], suggesting that physical activity may be beneficial for the cardiovascular system through FoxO proteins. Yet, other work has shown that Sirt1 may repress the activity of FoxO1, FoxO3a, and FoxO4, suggesting that cellular longevity may benefit from reduction in FoxO protein generated apoptosis [333].

Figure 5. Nicotinamide relies upon novel cellular pathways to impact cell survival, longevity, and immune system function. Nicotinamide controls apoptotic early phosphatidylserine exposure, DNA repair and degradation, cell longevity, and immune cell activation through multiple pathways that involve modulation of sirtuin activity, protein kinase B (Akt), poly (ADP-ribose) polymerase (PARP), forkhead transcription factors, mitochondrial membrane potential $\left(\Delta \Psi_{\mathrm{m}}\right)$, cytochrome $\mathrm{c}$, (Cyto-c), and caspases 1,3, 8, and 9. These pathways can then regulate the onset of early apoptotic injury with phosphatidylserine exposure, late injury with nuclear DNA degradation, and inflammatory cell activation.

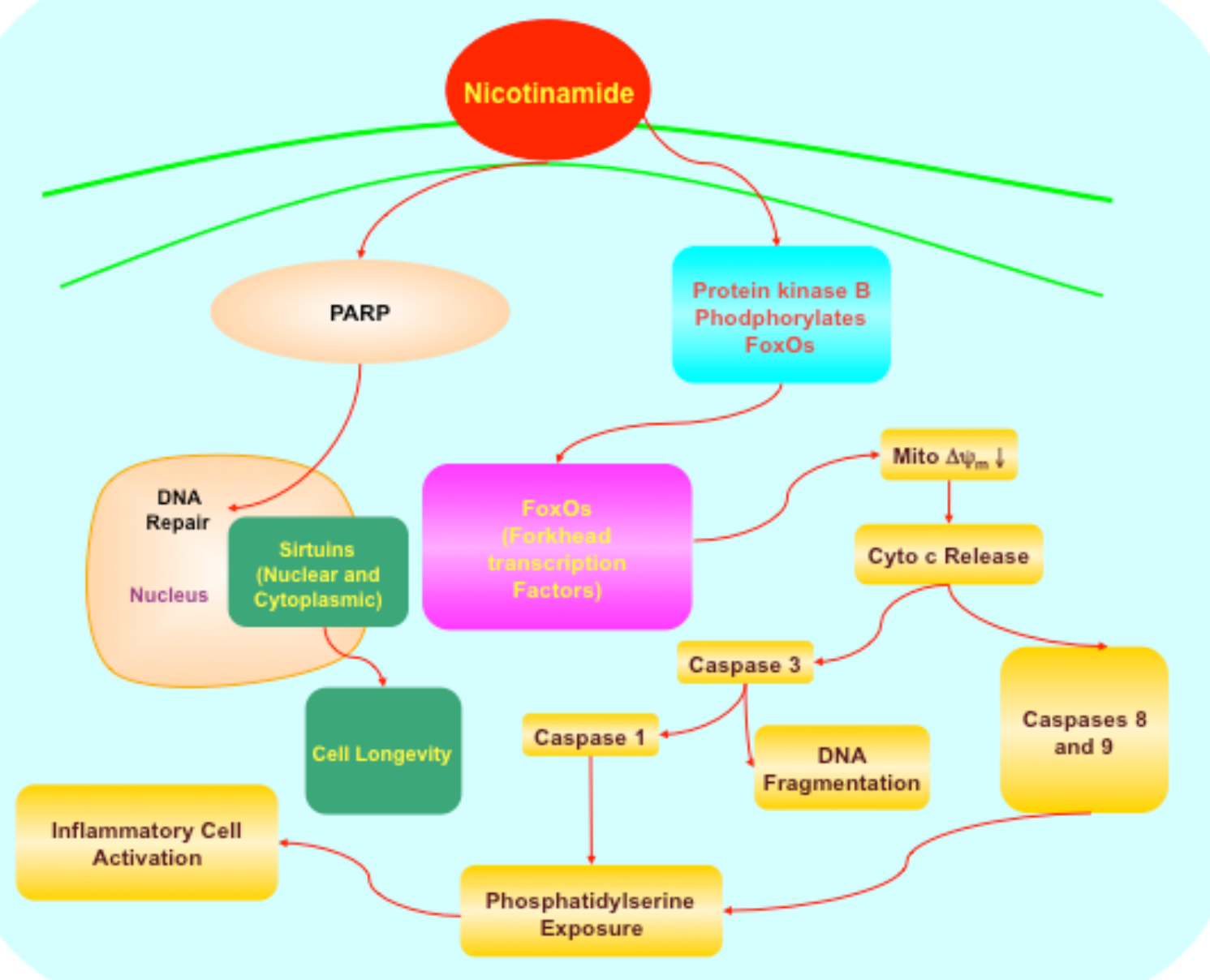

In regards to nicotinamide, cellular protection and longevity, it appears that a reduction in nicotinamide levels during nicotinamidase expression supports increased cellular survival and longevity [334,335] (Figure 5). Nicotinamide can block cellular Sir2 by intercepting an ADP-ribosylenzyme-acetyl peptide intermediate with the regeneration of $\mathrm{NAD}^{+}$(transglycosidation) [336]. Nicotinamidase expression which reduces nicotinamide concentrations prevents both apoptotic late 
DNA degradation and early PS exposure that may serve to modulate inflammatory cell activation. In addition, inhibition of sirtuin (Sirt1) activity either by pharmacological methods or siRNA gene silencing is detrimental to cell survival during oxidative stress and blocks nicotinamidase protection, further supporting that Sirt1 activity may be necessary for nicotinamidase protection during oxidative stress. Furthermore, nicotinamide offers gene regulation [337] and cellular protection in millimole concentrations against oxidative stress. Physiological concentrations of nicotinamide noncompetitively inhibit Sir2, suggesting that nicotinamide is a physiologically relevant regulator of Sir2 enzymes [338]. As a result, in relation to cell longevity, it is the lower concentrations of nicotinamide that can function as an inhibitor of sirtuins that are necessary for the promotion of increased lifespan and cellular survival [132-134,140,334,335,339], at least in yeast and metazoans [76,340,341]. Interestingly, it has been postulated that sirtuins also may prevent nicotinamide from assisting with DNA repair by altering the accessibility of DNA damaged sites for repair enzymes [342].

\subsection{Protein kinase B (Akt), Bad, caspases, and mitogen-activated protein kinases}

Post-translational modulation of FoxO proteins occurs through phosphorylation, acetylation, and ubiquitylation [306,326]. The serine-threonine kinase protein kinase B (Akt) is a principal pathway of phosphorylation of FoxOs that can block activity of these proteins [305,343]. Activation of Akt is usually "pro-survival" and cytoprotective, such as during cell proliferation [344], hyperglycemia [345], ischemia/stress [346,347], hypoxia [216], $\beta$-amyloid (A $\beta$ ) toxicity [25], cardiomyopathy [348], cellular aging [349], neurodegeneration [350,351], and oxidative stress [49,52,74]. Akt can prevent cellular apoptosis through the phosphorylation of FoxO proteins [117,309] and maintain FoxO transcription factors in the cytoplasm by association with 14-3-3 proteins and prevent the transcription of pro-apoptotic target genes [199,248].

Cytoprotection through Akt also can involve control of apoptotic inflammatory cell activation $[52,74,208]$, maintenance of mitochondrial membrane potential $\left(\Delta \Psi_{\mathrm{m}}\right)$, and prevention of cytochrome c release $[64,78,208]$. Akt can prevent early apoptotic membrane PS exposure on injured cells and block the activation of microglia during oxidative stress [52,71,74]. Nicotinamide uses mechanisms that involve Akt to regulate microglial activation and proliferation $[133,140]$ by blocking membrane PS exposure on cells and possibly preventing the shedding of membrane PS residues that is known to occur during apoptosis [352] (Figure 5).

Akt also regulates pathways that involve Bad, a pro-apoptotic Bcl-2 family member that becomes active through phosphorylation on its serine residues [83]. Phosphorylation of Bad by Akt leads to the binding of Bad with the cytosolic protein 14-3-3 to release Bcl- $\mathrm{x}_{\mathrm{L}}$ and allows Akt to block apoptosis [353]. Bcl-2 and Bcl- $\mathrm{x}_{\mathrm{L}}$ block Bax translocation to the mitochondria, maintain mitochondrial membrane potential, and prevent the release of cytochrome c from the mitochondria [208,354]. Nicotinamide can promote the phosphorylation of Bad during oxidative stress [133]. This phosphorylation of Bad by nicotinamide can be blocked by lack of Akt activity, suggesting that nicotinamide phosphorylates Bad through an Akt mediated pathway [343]. In addition, Akt may promote cell survival through the inhibition of apoptotic p53 transcriptional activity [355] that may be regulated by nicotinamide. Nicotinamide also has been shown to either directly limit the expression of p53 [153] or prevent an NAD-dependent p53 deacetylation induced by Sir2 $\alpha$ [356]. 
Since Akt can prevent caspase activity [78,208,216], it is conceivable to assume that nicotinamide also may regulate caspase activity. Caspases are a family of cysteine proteases that are synthesized as inactive zymogens which are proteolytically cleaved into subunits during apoptosis [76,357,358]. The apoptotic-associated caspases include initiator caspases, such as caspase 2, 8, 9, and 10, that activate downstream effector caspases, resulting in an amplification of cascade activity. The initiator caspases consist of long $\mathrm{N}$-terminal prodomains that contain caspase recruitment domains (CARDs) in caspase 2 and caspase 9 or death effector domains (DEDs) in caspase 8 and caspase 10. The effector caspases consist of caspase 3,6 , and 7 that function to directly cleave crucial cellular protein substrates to result in cell destruction $[55,83,142,357]$. Caspase 8 is as an upstream initiator of executioner caspases, such as caspase 3 , and also leads to the mitochondrial release of cytochrome c [359,360]. Following caspase 8 and caspase 9 activation, caspase 3 directly leads to genomic DNA degradation [52,74,78].

Caspases 1 and 3 mediate genomic DNA cleavage and cellular membrane PS exposure [64,208, 361]. These caspases $[4,134,135,141]$, in addition to caspase 8 and 9 , are also tied to the direct activation and proliferation of microglia $[52,74,78]$. Caspase 1 is believed to be principally responsible for the externalization of membrane PS residues in several cell systems that can subsequently activate microglial phagocytosis [80,362]. Furthermore, caspase 9 is activated through a process that involves the cytochrome c -apoptotic protease-activating factor-1 (Apaf-1) complex [79,363]. In regards to membrane PS exposure, nicotinamide prevents PS externalization primarily through the inhibition of caspase 1 -like activity [133] (Figure 5). Nicotinamide also prevents genomic DNA cleavage as well as early membrane PS exposure through caspase 8 and caspase 9 - like activities [4,133-135,140]. The precise pathways that are necessary for nicotinamide to modulate caspase pathways remain under investigation. Although some "anti-apoptotic" proteins, such as EPO [199,208] modulate both Apaf-1 expression and cytochrome c release, protection through nicotinamide remains independent from Apaf-1 [140]. However, nicotinamide can significantly prevent cell injury by inhibiting caspase 9 like activity directly [140].

Nicotinamide also relies upon the stress activated family of mitogen-activated protein kinases (MAPK) that includes the $\mathrm{p} 38$ kinases $\left(\mathrm{MAPK}^{\mathrm{p} 38}\right.$ ) and the c-Jun N-terminal kinases (MAPK ${ }^{\mathrm{JNK}}$ ). The family of MAPKs consists of the subgroups that include ERK1 (MAPK ${ }^{\mathrm{ERK} 1 / \mathrm{p} 44}$ ), ERK2 $\left(\mathrm{MAPK}^{\mathrm{ERK} 2 / \mathrm{p} 42}\right)$, the JNKs $\left(\mathrm{MAPK}^{\mathrm{JNK}}\right)$, and p38 MAPKs $\left(\mathrm{MAPK}^{\mathrm{p} 38}\right)$. Although significant activation of $\mathrm{MAPK}^{\mathrm{p} 38}$ and MAPK ${ }^{\mathrm{JNK}}$ is present in cells during oxidative stress [4,132,135,141] and c-Jun leads to apoptosis through transcription activation of some pro-apoptotic genes [364], nicotinamide does not appear to alter the activity of either $\mathrm{MAPK}^{\mathrm{p} 38}$ or $\mathrm{MAPK}^{\mathrm{JNK}}$ [133]. These results suggest that nicotinamide cytoprotection does not require the $\mathrm{MAPK}^{\mathrm{p} 38}$ and MAPK ${ }^{\mathrm{JNK}}$ pathways $[4,132,135,141]$.

\subsection{Poly (ADP-ribose) polymerase (PARP)}

Nicotinamide has an intimate relationship with poly (ADP-ribose) polymerase (PARP) that also been recently associated with both vascular and neurodegenerative disorders [76,174,365] (Figure 5). PARP is a nuclear protein that binds to DNA strand breaks and cleaves $\mathrm{NAD}^{+}$into nicotinamide and ADP-ribose. PARP catalyses the synthesis of poly (ADP-ribose) from its substrate $\mathrm{NAD}^{+}$, which stimulates the process of DNA repair [366]. Nicotinamide concentrations of at least $1 \mathrm{mM}$ have been shown to provide sufficient stores of $\mathrm{NAD}^{+}$for PARP activation [367]. Nicotinamide can prevent 
PARP degradation and allow for DNA repair through the direct inhibition of caspase 3 [133-135]. In contrast, elevated concentrations of nicotinamide can lead to PARP degradation and apoptotic injury [368].

However, other work illustrates that a reduction in PARP activity may enhance cell survival, such as during injury paradigms with photoreceptor cells [369], during homocysteine toxicity [370], during cerebral ischemia [371], or during free radical injury [372,373]. Prevention of $\mathrm{NAD}^{+}$depletion during enhanced PARP activity also has been demonstrated to prevent cellular lysis during oxidative stress [374]. In human blood lymphocytes during oxidative stress, nicotinamide may block necrotic death through pathways that limit excessive PARP activity that can consume essential $\mathrm{NAD}^{+}$stores [375]. During diabetic neuropathy, nicotinamide reduces PARP activity to partially restore vital $\mathrm{NAD}^{+}$and ATP [376].

Inhibition of PARP activity by nicotinamide also may be critical for disorders such as Alzheimer's disease. The National Institute on Aging estimates that almost five million people in the United States have Alzheimer's disease and worldwide more than twenty-four million people suffer from Alzheimer's disease, pre-senile dementia, and other disorders of cognitive loss. In Alzheimer's disease [99], $A \beta$ is toxic to cells $[25,26,121]$ and is associated with the phosphorylation of the forkhead transcription factors that can be blocked by scavengers of oxidative stress [377]. A prior pilot study has suggested that administration of nicotinamide adenine dinucleotide (NADH) in patients with Alzheimer's may show improvement in their cognitive function [378]. More recently, dietary niacin intake examined in a series of patients aged 65 and older has been implicated as a protectant against the development or progression of Alzheimer's disease [379]. Interestingly, it has been shown that in patients with Alzheimer's disease, both PARP and poly(ADP-ribose) is present in the frontal and temporal cortex more frequently than in controls, suggesting that increased levels of functional PARP enzyme are present to potentially lead to the depletion of $\mathrm{NAD}^{+}$stores [380]. In addition, $\mathrm{A} \beta$ toxicity may require increased PARP activity [381].

\section{Conclusions}

Therapeutic innovation relies heavily upon the understanding and emerging knowledge of the cellular pathways that govern disease. Yet, no therapeutic modality can be used with clear focus and caution to gain the greatest clinical efficacy with the least amount of unwanted detrimental effects. As a result, nicotinamide clearly comes under such constraints. As an agent that offers broad cytoprotective effects that may be applicable to multiple disorders of the cardiovascular, nervous, immune, and metabolic pathways, nicotinamide also has complex biological roles. For example, nicotinamide pathways that rely upon FoxO modulation may not consistently lead to controlled enhanced cell survival, but rather with unchecked cellular proliferation that leads to cancer. Furthermore, nicotinamide offers a fine line with concentration administration with lower concentrations of nicotinamide possibly negating sirtuin activity and decreasing lifespan in organisms. In addition, protection against PARP or preservation of its activity by nicotinamide also may sometimes lead to unwanted outcomes. PARP activation can deplete $\mathrm{NAD}^{+}$, lower ATP production, and precipitate cell death. Under other conditions, nicotinamide has been described as an agent that limits cell growth and promotes cell injury. Nicotinamide in the presence of transforming growth 
factor B-1 can block hepatic cell proliferation and lead to apoptosis with caspase 3 activation [265]. During moderate temperature hyperthermia or carbogen breathing, nicotinamide also can result in enhanced solid tumor radiosensitivity and assist with tumor load reduction [382]. With these considerations for nicotinamide, it is clear that this agent holds great potential for multiple disease entities, but the development of new therapeutic strategies with nicotinamide rests heavily upon the elucidation of the intimate relationship nicotinamide holds with novel pathways that include forkhead transcription factors, sirtuins, Akt, caspases, MAPK, and PARP.

\section{Acknowledgments}

This research was supported by the following grants (KM): American Diabetes Association, American Heart Association (National), Bugher Foundation Award, Janssen Neuroscience Award, LEARN Foundation Award, MI Life Sciences Challenge Award, Nelson Foundation Award, NIH NIEHS (P30 ES06639), NIH NIA, and NIH NINDS.

\section{References and Notes}

1. DiPalma, J.R.; Thayer, W.S. Use of niacin as a drug. Annu. Rev. Nutr. 1991, 11, 169-187.

2. Rex, A.; Fink, H. Pharmacokinetic aspects of reduced nicotinamide adenine dinucleotide (NADH) in rats. Front. Biosci. 2008, 13, 3735-3741.

3. Li, F.; Chong, Z.Z.; Maiese, K. Navigating novel mechanisms of cellular plasticity with the $\mathrm{NAD}+$ precursor and nutrient nicotinamide. Front. Biosci. 2004, 9, 2500-2520.

4. Maiese, K.; Chong, Z.Z. Nicotinamide: necessary nutrient emerges as a novel cytoprotectant for the brain. Trends Pharmacol. Sci. 2003, 24, 228-232.

5. Jackson, T.M.; Rawling, J.M.; Roebuck, B.D.; Kirkland, J.B. Large supplements of nicotinic acid and nicotinamide increase tissue NAD + and poly(ADP-ribose) levels but do not affect diethylnitrosamine-induced altered hepatic foci in Fischer-344 rats. J. Nutr. 1995, 125, 1455 1461.

6. Wojcik, M.; Seidle, H.F.; Bieganowski, P.; Brenner, C. Glutamine-dependent NAD+ synthetase. How a two-domain, three-substrate enzyme avoids waste. J. Biol. Chem. 2006, 281, 33395-33402.

7. Khan, J.A.; Forouhar, F.; Tao, X.; Tong, L. Nicotinamide adenine dinucleotide metabolism as an attractive target for drug discovery. Expert Opin. Ther. Targets 2007, 11, 695-705.

8. Khan, J.A.; Xiang, S.; Tong, L. Crystal structure of human nicotinamide riboside kinase. Structure 2007, 15, 1005-1013.

9. Depeint, F.; Bruce, W.R.; Shangari, N.; Mehta, R.; O'Brien, P.J. Mitochondrial function and toxicity: role of the B vitamin family on mitochondrial energy metabolism. Chem. Biol. Interact. 2006, 163, 94-112.

10. Hara, N.; Yamada, K.; Shibata, T.; Osago, H.; Hashimoto, T.; Tsuchiya, M. Elevation of cellular NAD levels by nicotinic acid and involvement of nicotinic acid phosphoribosyltransferase in human cells. J. Biol. Chem. 2007, 282, 24574-24582.

11. Williams, A.C.; Ramsden, D.B. Pellagra: A clue as to why energy failure causes diseases? Med. Hypotheses 2007, 69, 618-628. 
12. Williams, A.C.; Ramsden, D.B. Hydrogen symbioses in evolution and disease. QJM 2007, 100, 451-459.

13. El-Mir, M.Y.; Detaille, D.; G, R.V.; Delgado-Esteban, M.; Guigas, B.; Attia, S.; Fontaine, E.; Almeida, A.; Leverve, X. Neuroprotective role of antidiabetic drug metformin against apoptotic cell death in primary cortical neurons. J. Mol. Neurosci. 2008, 34, 77-87.

14. Kui, L.; Weiwei, Z.; Ling, L.; Daikun, H.; Guoming, Z.; Linuo, Z.; Renming, H. Ghrelin inhibits apoptosis induced by high glucose and sodium palmitate in adult rat cardiomyocytes through the PI3K-Akt signaling pathway. Regul. Pept. 2009, 155, 62-69.

15. Maiese, K.; Chong, Z.Z.; Shang, Y.C. Mechanistic insights into diabetes mellitus and oxidative stress. Curr. Med. Chem. 2007, 14, 1729-1738.

16. Maiese, K.; Morhan, S.D.; Chong, Z.Z. Oxidative stress biology and cell injury during type 1 and type 2 diabetes mellitus. Curr. Neurovasc. Res. 2007, 4, 63-71.

17. Han, Z.; Xiao, M.J.; Shao, B.; Zheng, R.Y.; Yang, G.Y.; Jin, K. Attenuation of ischemia-induced rat brain injury by 2-(-2-benzofuranyl)-2-imidazoline, a high selectivity ligand for imidazoline I(2) receptors. Neurol. Res. 2009, 31, 390-395.

18. Maiese, K. From the Bench to the Bedside: The Molecular Management of Cerebral Ischemia. Clin. Neuropharmacol. 1998, 21, 1-7.

19. Maiese, K.; Pek, L.; Berger, S.B.; Reis, D.J. Reduction in focal cerebral ischemia by agents acting at imidazole receptors. J. Cereb. Blood Flow Metab. 1992, 12, 53-63.

20. Nakka, V.P.; Gusain, A.; Mehta, S.L.; Raghubir, R. Molecular mechanisms of apoptosis in cerebral ischemia: multiple neuroprotective opportunities. Mol. Neurobiol. 2008, 37, 7-38.

21. Cardoso, L.; Herman, B.C.; Verborgt, O.; Laudier, D.; Majeska, R.J.; Schaffler, M.B. Osteocyte apoptosis controls activation of intracortical resorption in response to bone fatigue. J. Bone Miner. Res. 2009, 24, 597-605.

22. Burgos-Ramos, E.; Puebla-Jimenez, L.; Arilla-Ferreiro, E. Minocycline provides protection against beta-amyloid(25-35)-induced alterations of the somatostatin signaling pathway in the rat temporal cortex. Neuroscience 2008, 154, 1458-1466.

23. Burgos-Ramos, E.; Puebla-Jimenez, L.; Arilla-Ferreiro, E. Minocycline prevents Abeta(25-35)induced reduction of somatostatin and neprilysin content in rat temporal cortex. Life Sci. 2009, 84, 205-210.

24. Casoli, T.; Di Stefano, G.; Giorgetti, B.; Grossi, Y.; Balietti, M.; Fattoretti, P.; Bertoni-Freddari, C. Release of beta-amyloid from high-density platelets: implications for Alzheimer's disease pathology. Ann. N. Y. Acad. Sci, 2007, 1096, 170-178.

25. Chong, Z.Z.; Li, F.; Maiese, K. Erythropoietin requires NF-kappaB and its nuclear translocation to prevent early and late apoptotic neuronal injury during beta-amyloid toxicity. Curr. Neurovasc. Res. 2005, 2, 387-399.

26. Chong, Z.Z.; Li, F.; Maiese, K. Cellular demise and inflammatory microglial activation during beta-amyloid toxicity are governed by Wnt1 and canonical signaling pathways. Cell. Signal. 2007, 19, 1150-1162.

27. Kelley, B.J.; Knopman, D.S. Alternative medicine and Alzheimer disease. Neurologist 2008, 14, 299-306. 
28. Liang, W.S.; Dunckley, T.; Beach, T.G.; Grover, A.; Mastroeni, D.; Ramsey, K.; Caselli, R.J.; Kukull, W.A.; McKeel, D.; Morris, J.C.; Hulette, C.M.; Schmechel, D.; Reiman, E.M.; Rogers, J.; Stephan, D.A. Altered neuronal gene expression in brain regions differentially affected by Alzheimer's disease: a reference data set. Physiol. Genomics 2008, 33, 240-256.

29. Majd, S.; Rastegar, K.; Zarifkar, A.; Takhshid, M.A. Fibrillar beta-amyloid (Abeta) (1-42) elevates extracellular Abeta in cultured hippocampal neurons of adult rats. Brain Res. 2007, 1185, 321-327.

30. Majd, S.; Zarifkar, A.; Rastegar, K.; Takhshid, M.A. Different fibrillar Abeta 1-42 concentrations induce adult hippocampal neurons to reenter various phases of the cell cycle. Brain Res. 2008, 1218, 224-229.

31. Vaisid, T.; Barnoy, S.; Kosower, N.S. Calpastatin overexpression attenuates amyloid-betapeptide toxicity in differentiated PC12 cells. Neuroscience 2008, 156, 921-931.

32. Verdaguer, E; Susana Gde, A.; Clemens, A.; Pallas, M.; Camins, A. Implication of the transcription factor E2F-1 in the modulation of neuronal apoptosis. Biomed. Pharmacother. 2007, 61, 390-399.

33. Arboleda, G.; Morales, L.C.; Benitez, B.; Arboleda, H. Regulation of ceramide-induced neuronal death: cell metabolism meets neurodegeneration. Brain Res. Rev. 2009, 59, 333-346.

34. Maiese, K. Triple play: Promoting neurovascular longevity with nicotinamide, WNT, and erythropoietin in diabetes mellitus. Biomed. Pharmacother. 2008, 62, 218-232.

35. Maiese, K.; Vincent, A.M. Critical temporal modulation of neuronal programmed cell injury. Cell. Mol. Neurobiol. 2000, 20, 383-400.

36. Zhong, J.; Zheng, W.; Huang, L.; Hong, Y.; Wang, L.; Qiu, Y.; Sha, Y. PrP106-126 amide causes the semi-penetrated poration in the supported lipid bilayers. Biochim. Biophys. Acta 2007, 1768, 1420-1429.

37. Sommer, C. Neuronal plasticity after ischemic preconditioning and TIA-like preconditioning ischemic periods. Acta Neuropathol. 2009, 117, 511-523.

38. Braga, M.; Sinha Hikim, A.P.; Datta, S.; Ferrini, M.G.; Brown, D.; Kovacheva, E.L.; GonzalezCadavid, N.F.; Sinha-Hikim, I. Involvement of oxidative stress and caspase 2-mediated intrinsic pathway signaling in age-related increase in muscle cell apoptosis in mice. Apoptosis 2008, 13, 822-832.

39. Maiese, K.; Chong, Z.; Li, F. Reducing Oxidative Stress and Enhancing Neurovascular Longevity During Diabetes Mellitus. In Neurovascular Medicine: Pursuing Cellular Longevity for Healthy Aging; Maiese, K. Ed.; Oxford University Press: New York, NY, USA, 2009; pp. 540-564.

40. Maiese, K.; Chong, Z.Z.; Kang, J. Transformation into Treatment: Novel Therapeutics that begin within the Cell. In Neuronal and Vascular Plasticity: Elucidating Basic Cellular Mechanisms for Future Therapeutic Discovery; Maiese, K. Ed.; Kluwer Academic Publishers: Norwell, MA, USA, 2003; pp. 1-26.

41. Gross, J.; Machulik, A.; Amarjargal, N.; Moller, R.; Ungethum, U.; Kuban, R.J.; Fuchs, F.U.; Andreeva, N.; Fuchs, J.; Henke, W.; Pohl, E.E.; Szczepek, A.J.; Haupt, H.; Mazurek, B. Expression of apoptosis-related genes in the organ of Corti, modiolus and stria vascularis of newborn rats. Brain Res. 2007, 1162, 56-68. 
42. Head, B.P.; Patel, H.H.; Niesman, I.R.; Drummond, J.C.; Roth, D.M.; Patel, P.M. Inhibition of p75 neurotrophin receptor attenuates isoflurane-mediated neuronal apoptosis in the neonatal central nervous system. Anesthesiology 2009, 110, 813-825.

43. Bogaerts, V.; Nuytemans, K.; Reumers, J.; Pals, P.; Engelborghs, S.; Pickut, B.; Corsmit, E.; Peeters, K.; Schymkowitz, J.; De Deyn, P.P.; Cras, P.; Rousseau, F.; Theuns, J.; Van Broeckhoven, C. Genetic variability in the mitochondrial serine protease HTRA2 contributes to risk for Parkinson disease. Hum. Mutat. 2008, 29, 832-840.

44. He, X.L.; Wang, Y.H.; Gao, M.; Li, X.X.; Zhang, T.T.; Du, G.H. Baicalein protects rat brain mitochondria against chronic cerebral hypoperfusion-induced oxidative damage. Brain Res. 2009, 1249, 212-221.

45. Maiese, K.; Chong, Z.Z.; Shang, Y.C.; Hou, J. Therapeutic promise and principles: Metabotropic glutamate receptors. Oxid. Med. Cell. Longev. 2008, 1, 1-14.

46. Plecita-Hlavata, L.; Lessard, M.; Santorova, J.; Bewersdorf, J.; Jezek, P. Mitochondrial oxidative phosphorylation and energetic status are reflected by morphology of mitochondrial network in INS-1E and HEP-G2 cells viewed by 4Pi microscopy. Biochim. Biophys. Acta 2008, 1777, 834-846.

47. Hao, J.; Shen, W.; Tian, C.; Liu, Z.; Ren, J.; Luo, C.; Long, J.; Sharman, E.; Liu, J. Mitochondrial nutrients improve immune dysfunction in the type 2 diabetic Goto-Kakizaki rats. J. Cell. Mol. Med. 2009, 13, 701-711.

48. Parihar, M.S.; Brewer, G.J. Mitoenergetic failure in Alzheimer disease. Am. J. Physiol. Cell. Physiol. 2007, 292, C8-23.

49. Chong, Z.Z.; Kang, J.Q.; Maiese, K. Akt1 drives endothelial cell membrane asymmetry and microglial activation through $\mathrm{Bcl}-\mathrm{x}(\mathrm{L})$ and caspase 1, 3, and 9. Exp. Cell. Res. 2004, 296, 196-207.

50. Chong, Z.Z.; Li, F.; Maiese, K. The pro-survival pathways of mTOR and protein kinase B target glycogen synthase kinase-3beta and nuclear factor-kappaB to foster endogenous microglial cell protection. Int. J. Mol. Med. 2007, 19, 263-272.

51. Harris, S.E.; Fox, H.; Wright, A.F.; Hayward, C.; Starr, J.M.; Whalley, L.J.; Deary, I.J. A genetic association analysis of cognitive ability and cognitive ageing using 325 markers for 109 genes associated with oxidative stress or cognition. BMC Genet. 2007, 8, 43.

52. Kang, J.Q.; Chong, Z.Z.; Maiese, K. Critical role for Akt1 in the modulation of apoptotic phosphatidylserine exposure and microglial activation. Mol. Pharmacol. 2003, 64, 557-569.

53. Karunakaran, S.; Diwakar, L.; Saeed, U.; Agarwal, V.; Ramakrishnan, S.; Iyengar, S.; Ravindranath, V. Activation of apoptosis signal regulating kinase 1 (ASK1) and translocation of death-associated protein, Daxx, in substantia nigra pars compacta in a mouse model of Parkinson's disease: protection by alpha-lipoic acid. Faseb. J. 2007, 21, 2226-2236.

54. Chong, Z.Z.; Li, F.; Maiese, K. Employing new cellular therapeutic targets for Alzheimer's disease: a change for the better? Curr. Neurovasc. Res. 2005, 2, 55-72.

55. Maiese, K.; Chong, Z.Z.; Shang, Y.C.; Hou, J. Rogue proliferation versus restorative protection: where do we draw the line for Wnt and forkhead signaling? Expert Opin. Ther. Targets 2008, 12, 905-916. 
56. Maiese, K.; Vincent, A.; Lin, S.H.; Shaw, T. Group I and Group III metabotropic glutamate receptor subtypes provide enhanced neuroprotection. J. Neurosci. Res. 2000, 62, 257-272.

57. Mari, C.; Karabiyikoglu, M.; Goris, M.L.; Tait, J.F.; Yenari, M.A.; Blankenberg, F.G. Detection of focal hypoxic-ischemic injury and neuronal stress in a rodent model of unilateral MCA occlusion/reperfusion using radiolabeled annexin V. Eur. J. Nucl. Med. Mol. Imaging 2004, 31, 733-739.

58. Lin, S.H.; Chong, Z.Z.; Maiese, K. Cell cycle induction in post-mitotic neurons proceeds in concert with the initial phase of programmed cell death in rat. Neurosci. Lett. 2001, 310, 173-177.

59. Lin, S.H.; Maiese, K. The metabotropic glutamate receptor system protects against ischemic free radical programmed cell death in rat brain endothelial cells. J. Cereb. Blood Flow Metab. 2001, 21, 262-275.

60. Maiese, K. The dynamics of cellular injury: transformation into neuronal and vascular protection. Histol. Histopathol. 2001, 16, 633-644.

61. Maiese, K.; Ahmad, I.; TenBroeke, M.; Gallant, J. Metabotropic glutamate receptor subtypes independently modulate neuronal intracellular calcium. J. Neurosci. Res. 1999, 55, 472-485.

62. Vincent, A.M.; Maiese, K. Direct temporal analysis of apoptosis induction in living adherent neurons. J. Histochem. Cytochem. 1999, 47, 661-672.

63. Shang, Y.C.; Chong, Z.Z.; Hou, J.; Maiese, K. The forkhead transcription factor FoxO3a controls microglial inflammatory activation and eventual apoptotic injury through caspase 3. Curr. Neurovasc. Res. 2009, 6, 20-31.

64. Chong, Z.Z.; Lin, S.H.; Kang, J.Q.; Maiese, K. Erythropoietin prevents early and late neuronal demise through modulation of Akt1 and induction of caspase 1, 3, and 8. J. Neurosci. Res. 2003, 71, 659-669.

65. Chong, Z.Z.; Lin, S.H.; Kang, J.Q.; Maiese, K. The tyrosine phosphatase SHP2 modulates MAP kinase p38 and caspase 1 and 3 to foster neuronal survival. Cell. Mol. Neurobiol. 2003, 23, 561-578.

66. Maiese, K.; Boccone, L. Neuroprotection by peptide growth factors against anoxia and nitric oxide toxicity requires modulation of protein kinase C. J. Cereb. Blood Flow Metab. 1995, 15, 440-449.

67. Maiese, K.; Boniece, I.R.; Skurat, K.; Wagner, J.A. Protein kinases modulate the sensitivity of hippocampal neurons to nitric oxide toxicity and anoxiA.J. Neurosci. Res. 1993, 36, 77-87.

68. Maiese, K.; TenBroeke, M.; Kue, I. Neuroprotection of lubeluzole is mediated through the signal transduction pathways of nitric oxide. J. Neurochem. 1997, 68, 710-714.

69. Rodriguez-Blanco, J.; Martin, V.; Herrera, F.; Garcia-Santos, G.; Antolin, I.; Rodriguez, C. Intracellular signaling pathways involved in post-mitotic dopaminergic PC12 cell death induced by 6-hydroxydopamine. J. Neurochem. 2008, 107, 127-140.

70. Leytin, V.; Allen, D.J.; Mykhaylov, S.; Lyubimov, E.; Freedman, J. Thrombin-triggered platelet apoptosis. J. Thromb. Haemost. 2006, 4, 2656-2663.

71. Chong, Z.Z.; Kang, J.; Li, F.; Maiese, K. mGluRI Targets Microglial Activation and Selectively Prevents Neuronal Cell Engulfment Through Akt and Caspase Dependent Pathways. Curr. Neurovasc. Res. 2005, 2, 197-211. 
72. Li, F.; Chong, Z.Z.; Maiese, K. Microglial integrity is maintained by erythropoietin through integration of Akt and its substrates of glycogen synthase kinase-3beta, beta-catenin, and nuclear factor-kappaB. Curr. Neurovasc. Res. 2006, 3, 187-201.

73. Chong, Z.Z.; Kang, J.Q.; Maiese, K. Metabotropic glutamate receptors promote neuronal and vascular plasticity through novel intracellular pathways. Histol. Histopathol. 2003, 18, 173-189.

74. Kang, J.Q.; Chong, Z.Z.; Maiese, K. Akt1 protects against inflammatory microglial activation through maintenance of membrane asymmetry and modulation of cysteine protease activity. $J$. Neurosci. Res. 2003, 74, 37-51.

75. Mallat, M.; Marin-Teva, J.L.; Cheret, C. Phagocytosis in the developing CNS: more than clearing the corpses. Curr. Opin. Neurobiol. 2005, 15, 101-107.

76. Li, F.; Chong, Z.Z.; Maiese, K. Cell Life Versus Cell Longevity: The Mysteries Surrounding the NAD(+) Precursor Nicotinamide. Curr. Med. Chem. 2006, 13, 883-895.

77. Li, F.; Chong, Z.Z.; Maiese, K. Winding through the WNT pathway during cellular development and demise. Histol. Histopathol. 2006, 21, 103-124.

78. Chong, Z.Z.; Kang, J.Q.; Maiese, K. Erythropoietin fosters both intrinsic and extrinsic neuronal protection through modulation of microglia, Akt1, Bad, and caspase-mediated pathways. Br. $J$. Pharmacol. 2003, 138, 1107-1118.

79. Chong, Z.Z.; Kang, J.Q.; Maiese, K. Essential cellular regulatory elements of oxidative stress in early and late phases of apoptosis in the central nervous system. Antioxid. Redox. Signal. 2004, 6, 277-287.

80. Maiese, K.; Vincent, A.M. Membrane asymmetry and DNA degradation: functionally distinct determinants of neuronal programmed cell death. J. Neurosci. Res. 2000, 59, 568-580.

81. Dombroski, D.; Balasubramanian, K.; Schroit, A.J. Phosphatidylserine expression on cell surfaces promotes antibody- dependent aggregation and thrombosis in beta2-glycoprotein Iimmune mice. J. Autoimmun. 2000, 14, 221-229.

82. Jessel, R.; Haertel, S.; Socaciu, C.; Tykhonova, S.; Diehl, H.A. Kinetics of apoptotic markers in exogeneously induced apoptosis of EL4 cells. J. Cell Mol. Med. 2002, 6, 82-92.

83. Chong, Z.Z.; Li, F.; Maiese, K. Oxidative stress in the brain: Novel cellular targets that govern survival during neurodegenerative disease. Prog. Neurobiol. 2005, 75, 207-246.

84. Chong, Z.Z.; Maiese, K. The Src homology 2 domain tyrosine phosphatases SHP-1 and SHP-2: diversified control of cell growth, inflammation, and injury. Histol. Histopathol. 2007, 22, 1251-1267.

85. Vincent, A.M.; Maiese, K. Nitric oxide induction of neuronal endonuclease activity in programmed cell death. Exp. Cell. Res. 1999, 246, 290-300.

86. Vincent, A.M.; TenBroeke, M.; Maiese, K. Metabotropic glutamate receptors prevent programmed cell death through the modulation of neuronal endonuclease activity and intracellular pH. Exp. Neurol. 1999, 155, 79-94.

87. Barbosa, N.B.; Oliveira, C.; Araldi, D.; Folmer, V.; Rocha, J.B.; Nogueira, C.W. Acute diphenyl diselenide treatment reduces hyperglycemia but does not change delta-aminolevulinate dehydratase activity in alloxan-induced diabetes in rats. Biol. Pharm. Bull. 2008, 31, 2200-2204. 
88. Duarte, A.I.; Santos, P.; Oliveira, C.R.; Santos, M.S.; Rego, A.C. Insulin neuroprotection against oxidative stress is mediated by Akt and GSK-3beta signaling pathways and changes in protein expression. Biochim. Biophys. Acta 2008, 1783, 994-1002.

89. Gossai, D.; Lau-Cam, C.A. The effects of taurine, taurine homologs and hypotaurine on cell and membrane antioxidative system alterations caused by type 2 diabetes in rat erythrocytes. Adv. Exp. Med. Biol. 2009, 643, 359-368.

90. Guarnieri, G.; Zanetti, M.; Vinci, P.; Cattin, M.R.; Barazzoni, R. Insulin resistance in chronic uremia. J. Ren. Nutr. 2009, 19, 20-24.

91. Maiese, K. Diabetic stress: new triumphs and challenges to maintain vascular longevity. Expert Rev. Cardiovasc. Ther. 2008, 6, 281-284.

92. Maiese, K. Marking the onset of oxidative stress: Biomarkers and novel strategies. Oxid. Med. Cell. Longev. 2009, 2, 1.

93. Ruf, T.F.; Quintes, S.; Sternik, P.; Gottmann, U. Atorvastatin reduces the expression of aldo-keto reductases in HUVEC and PTEC. A new approach to influence the polyol pathway. Clin. Invest. Med. 2009, 32, E219-228.

94. Szabo, C. Role of nitrosative stress in the pathogenesis of diabetic vascular dysfunction. Br. $J$. Pharmacol. 2009, 156, 713-727.

95. Wu, S.Y.; Wang, G.F.; Liu, Z.Q.; Rao, J.J.; Lu, L.; Xu, W.; Wu, S.G.; Zhang, J.J. Effect of geniposide, a hypoglycemic glucoside, on hepatic regulating enzymes in diabetic mice induced by a high-fat diet and streptozotocin. Acta. Pharmacol. Sin. 2009, 30, 202-208.

96. Kubo, E.; Fatma, N.; Akagi, Y.; Beier, D.R.; Singh, S.P.; Singh, D.P. TAT-mediated PRDX6 protein transduction protects against eye lens epithelial cell death and delays lens opacity. Am. J. Physiol. Cell. Physiol. 2008, 294, C842-855.

97. Probst-Hensch, N.M.; Imboden, M.; Felber, D.; Barthelemy, J.C.; Ackermann-Liebrich, U.; Berger, W.; Gaspoz, J.M.; Schwartz, J. Glutathione S-transferase polymorphisms, passive smoking, obesity, and heart rate variability in nonsmokers. Environ. Health Perspect. 2008, 116, 1494-1499.

98. Swan, G.E.; Lessov-Schlaggar, C.N. The effects of tobacco smoke and nicotine on cognition and the brain. Neuropsychol. Rev. 2007, 17, 259-273.

99. Erol, A. Unraveling the Molecular Mechanisms Behind the Metabolic Basis of Sporadic Alzheimer's Disease. J. Alzheimers Dis. 2009, 267-276.

100. Newman, M.; Musgrave, I.F.; Lardelli, M. Alzheimer disease: Amyloidogenesis, the presenilins and animal models. Biochim. Biophys. Acta 2007, 1772, 285-297.

101. Power, J.H.; Asad, S.; Chataway, T.K.; Chegini, F.; Manavis, J.; Temlett, J.A.; Jensen, P.H.; Blumbergs, P.C.; Gai, W.P. Peroxiredoxin 6 in human brain: molecular forms, cellular distribution and association with Alzheimer's disease pathology. Acta Neuropathol. 2008, 115, 611-622.

102. Toledano, A.; Alvarez, M.I.; Caballero, I.; Carmona, P.; De Miguel, E. Immunohistochemical increase in cyclooxygenase- 2 without apoptosis in different brain areas of subchronic nicotineand D-amphetamine-treated rats. J. Neural Transm. 2008, 115, 1093-1108. 
103. Park, S.J.; Kim, H.Y.; Kim, H.; Park, S.M.; Joe, E.H.; Jou, I.; Choi, Y.H. Oxidative stress induces lipid-raft-mediated activation of Src homology 2 domain-containing protein-tyrosine phosphatase 2 in astrocytes. Free Radic. Biol. Med. 2009, 46, 1694-1702.

104. Thomas, D.D.; Ridnour, L.A.; Isenberg, J.S.; Flores-Santana, W.; Switzer, C.H.; Donzelli, S.; Hussain, P.; Vecoli, C.; Paolocci, N.; Ambs, S.; Colton, C.A.; Harris, C.C.; Roberts, D.D.; Wink, D.A. The chemical biology of nitric oxide: implications in cellular signaling. Free Radic. Biol. Med. 2008, 45, 18-31.

105. Zhou, M.; Xu, W.; Liao, G.; Bi, X.; Baudry, M. Neuroprotection against neonatal hypoxia/ischemia-induced cerebral cell death by prevention of calpain-mediated mGluR1alpha truncation. Exp. Neurol. 2009, 218, 75-82.

106. Lehtinen, M.K.; Tegelberg, S.; Schipper, H.; Su, H.; Zukor, H.; Manninen, O.; Kopra, O.; Joensuu, T.; Hakala, P.; Bonni, A.; Lehesjoki, A.E. Cystatin B deficiency sensitizes neurons to oxidative stress in progressive myoclonus epilepsy, EPM1. J. Neurosci. 2009, 29, 5910-5915.

107. Sales Santos, I.; da Rocha Tomé, A.; Saldanha, G.; Ferreira, P.; Militão, G.; de Freitas, R. Oxidative stress in the hippocampus during experimental seizures can be ameliorated with the antioxidant ascorbic acid. Oxid. Med. Cell. Longev. 2009, 2, 23-30.

108. Bloomer, R.; Fisher-Wellman, K. Systemic oxidative stress is increased to a greater degree in young, obese women following consumption of a high fat meal. Oxid. Med. Cell. Longev. 2009, 2, 19-25.

109. Fisher-Wellman, K.; Bell, H.; Bloomer, R. Oxidative stress and antioxidant defense mechanisms linked to exercise during cardiopulmonary and metabolic disorders. Oxid. Med. Cell. Longev. 2009, 2, 43-51.

110. Gomes, P.; Simão, S.; Silva, E.; Pinto, V.; Amaral, J.S.; Afonso, J.; Serrão, M.P.; Pinho, M.J.; Soares-da-Silva, P. Aging increases oxidative stress and renal expression of oxidant and antioxidant enzymes that are associated with an increased trend in systolic blood pressure. Oxid. Med. Cell. Longev. 2009, 2, 19-26.

111. Nomoto, M.; Miyata, M.; Yin, S.; Kurata, Y.; Shimada, M.; Yoshinari, K.; Gonzalez, F.J.; Suzuki, K.; Shibasaki, S.; Kurosawa, T.; Yamazoe, Y. Bile acid-induced elevated oxidative stress in the absence of farnesoid X receptor. Biol. Pharm. Bull. 2009, 32, 172-178.

112. Bouayed, J.; Rammal, H.; Soulimani, R. Oxidative stress and anxiety: Relationship and cellular pathways. Oxid. Med. Cell. Longev. 2009, 2, 63-67.

113. Maiese, K. High anxiety: Recognizing stress as the stressor. Oxid. Med. Cell. Longev. 2009, 2, 61-62.

114. Ozsoy, N.; Candoken, E.; Akev, N. Implications for degenerative disorders: Antioxidative activity, total phenols, flavonoids, ascorbic acid, $\beta$-carotene, $\alpha$-tocopherol in Aloe vera. Oxid. Med. Cell. Longev. 2009, 2, 99-106.

115. Cheema, R.S.; Bansal, A.K.; Bilaspuri, G.S. Manganese provides antioxidant protection for sperm cryopreservation that may offer new consideration for clinical fertility. Oxid. Med. Cell. Longev. 2009, 2, 33-40.

116. Maiese, K.; Chong, Z.; Hou, J.; Shang, Y. The "O" Class: Crafting Clinical Care with FoxO Transcription Factors. In Forkhead Transcription Factors: Vital Elements in Biology and Medicine; Maiese, K., Ed.; Landes Bioscience: Austin, TX, USA, 2009; Vol. 665. 
117. Maiese, K.; Chong, Z.Z.; Shang, Y.C.; Hou, J.A. "FOXO" in sight: Targeting Foxo proteins from conception to cancer. Med. Res. Rev. 2009, 29, 395-418.

118. Campos-Esparza, M.R.; Sanchez-Gomez, M.V.; Matute, C. Molecular mechanisms of neuroprotection by two natural antioxidant polyphenols. Cell Calcium 2009, 45, 358-368.

119. He, Z.; Huang, L.; Wu, Y.; Wang, J.; Wang, H.; Guo, L. DDPH: improving cognitive deficits beyond its alpha 1-adrenoceptor antagonism in chronic cerebral hypoperfused rats. Eur. J. Pharmacol. 2008, 588, 178-188.

120. He, Z.; Lu, Q.; Xu, X.; Huang, L.; Chen, J.; Guo, L. DDPH ameliorated oxygen and glucose deprivation-induced injury in rat hippocampal neurons via interrupting $\mathrm{Ca}^{2+}$ overload and glutamate release. Eur. J. Pharmacol. 2009, 603, 50-55.

121. Lu, J.; Wu, D.M.; Zheng, Y.L.; Sun, D.X.; Hu, B.; Shan, Q.; Zhang, Z.F.; Fan, S.H. Trace amounts of copper exacerbate beta amyloid-induced neurotoxicity in the cholesterol-fed mice through TNF-mediated inflammatory pathway. Brain Behav. Immun. 2009, 23, 193-203.

122. North, B.J.; Marshall, B.L.; Borra, M.T.; Denu, J.M.; Verdin, E. The human Sir2 ortholog, SIRT2, is an NAD+-dependent tubulin deacetylase. Mol. Cell. 2003, 11, 437-444.

123. Rosa, R.M.; Hoch, N.C.; Furtado, G.V.; Saffi, J.; Henriques, J.A. DNA damage in tissues and organs of mice treated with diphenyl diselenide. Mutat. Res. 2007, 633, 35-45.

124. Pearl, R. The Rate of Living; University of London Press: London, UK, 1928.

125. Muller, F.L.; Lustgarten, M.S.; Jang, Y.; Richardson, A.; Van Remmen, H. Trends in oxidative aging theories. Free Radic. Biol. Med. 2007, 43, 477-503.

126. Yui, R.; Matsuura, E.T. Detection of deletions flanked by short direct repeats in mitochondrial DNA of aging Drosophila. Mutat. Res. 2006, 594, 155-161.

127. Maiese, K.; Chong, Z.Z.; Hou, J.; Shang, Y.C. Erythropoietin and oxidative stress. Curr. Neurovasc. Res. 2008, 5, 125-142.

128. Chong, Z.Z.; Li, F.; Maiese, K. Attempted Cell Cycle Induction in Post-Mitotic Neurons Occurs in Early and Late Apoptotic Programs Through Rb, E2F1, and Caspase 3. Curr. Neurovasc. Res. 2006, 3, 25-39.

129. De Felice, F.G.; Velasco, P.T.; Lambert, M.P.; Viola, K.; Fernandez, S.J.; Ferreira, S.T.; Klein, W.L. Abeta oligomers induce neuronal oxidative stress through an N-methyl-D-aspartate receptor-dependent mechanism that is blocked by the Alzheimer drug memantine. J. Biol. Chem. 2007, 282, 11590-11601.

130. Li, J.; Wang, H.; Rosenberg, P.A. Vitamin K prevents oxidative cell death by inhibiting activation of 12-lipoxygenase in developing oligodendrocytes. J. Neurosci. Res. 2009, 87, 1997-2005.

131. Then, S.M.; Mazlan, M.; Mat Top, G.; Wan Ngah, W.Z. Is vitamin E toxic to neuron cells? Cell. Mol. Neurobiol. 2009, 29, 485-496.

132. Lin, S.H.; Chong, Z.Z.; Maiese, K. Nicotinamide: A Nutritional Supplement that Provides Protection Against Neuronal and Vascular Injury. J. Med. Food 2001, 4, $27-38$.

133. Chong, Z.Z.; Lin, S.H.; Li, F.; Maiese, K. The sirtuin inhibitor nicotinamide enhances neuronal cell survival during acute anoxic injury through Akt, Bad, PARP, and mitochondrial associated "anti-apoptotic" pathways. Curr. Neurovasc. Res. 2005, 2, 271-285. 
134. Chong, Z.Z.; Lin, S.H.; Maiese, K. Nicotinamide Modulates Mitochondrial Membrane Potential and Cysteine Protease Activity during Cerebral Vascular Endothelial Cell Injury. J. Vasc. Res. 2002, 39, 131-147.

135. Lin, S.H.; Vincent, A.; Shaw, T.; Maynard, K.I.; Maiese, K. Prevention of nitric oxide-induced neuronal injury through the modulation of independent pathways of programmed cell death. $J$. Cereb. Blood Flow Metab. 2000, 20, 1380-1391.

136. Kiuchi, K.; Yoshizawa, K.; Shikata, N.; Matsumura, M.; Tsubura, A. Nicotinamide prevents Nmethyl-N-nitrosourea-induced photoreceptor cell apoptosis in Sprague-Dawley rats and C57BL mice. Exp. Eye Res. 2002, 74, 383-392.

137. Bombeli, T.; Karsan, A.; Tait, J.F.; Harlan, J.M. Apoptotic vascular endothelial cells become procoagulant. Blood 1997, 89, 2429-2442.

138. Chong, Z.Z.; Kang, J.Q.; Maiese, K. Angiogenesis and plasticity: role of erythropoietin in vascular systems. J. Hematother. Stem. Cell Res. 2002, 11, 863-871.

139. Maiese, K.; Chong, Z.Z.; Shang, Y.C. Raves and risks for erythropoietin. Cytokine Growth Factor Rev. 2008, 19, 145-155.

140. Chong, Z.Z.; Lin, S.H.; Maiese, K. The NAD+ precursor nicotinamide governs neuronal survival during oxidative stress through protein kinase B coupled to FOXO3a and mitochondrial membrane potential. J. Cereb. Blood Flow Metab. 2004, 24, 728-743.

141. Maiese, K.; Lin, S.; Chong, Z.Z. Elucidating neuronal and vascular injury through the cytoprotective agent nicotinamide. Curr. Med. Chem-Imm, Endoc. \& Metab. Agents 2001, 1, 257-267.

142. Chong, Z.Z.; Li, F.; Maiese, K. Stress in the brain: novel cellular mechanisms of injury linked to Alzheimer's disease. Brain Res. Rev. 2005, 49, 1-21.

143. Sensi, S.L.; Jeng, J.M. Rethinking the excitotoxic ionic milieu: the emerging role of $\mathrm{zn}(2+)$ in ischemic neuronal injury. Curr.Mol. Med. 2004, 4, 87-111.

144. Vincent, A.M.; TenBroeke, M.; Maiese, K. Neuronal intracellular pH directly mediates nitric oxide-induced programmed cell death. J. Neurobiol. 1999, 40, 171-184.

145. Aoyagi, S.; Archer, T.K. Nicotinamide uncouples hormone-dependent chromatin remodeling from transcription complex assembly. Mol. Cell Biol. 2008, 28, 30-39.

146. Bruno, V.; Battaglia, G.; Copani, A.; Giffard, R.G.; Raciti, G.; Raffaele, R.; Shinozaki, H.; Nicoletti, F. Activation of class II or III metabotropic glutamate receptors protects cultured cortical neurons against excitotoxic degeneration. Eur. J. Neurosci. 1995, 7, 1906-1913.

147. Anderson, D.W.; Bradbury, K.A.; Schneider, J.S. Neuroprotection in Parkinson models varies with toxin administration protocol. Eur. J. Neurosci. 2006, 24, 3174-3182.

148. Feng, Y.; Paul, I.A.; LeBlanc, M.H. Nicotinamide reduces hypoxic ischemic brain injury in the newborn rat. Brain Res. Bull. 2006, 69, 117-122.

149. Slomka, M.; Zieminska, E.; Salinska, E.; Lazarewicz, J.W. Neuroprotective effects of nicotinamide and 1-methylnicotinamide in acute excitotoxicity in vitro. Folia Neuropathol. 2008, 46, 69-80.

150. Slomka, M.; Zieminska, E.; Lazarewicz, J. Nicotinamide and 1-methylnicotinamide reduce homocysteine neurotoxicity in primary cultures of rat cerebellar granule cells. Acta Neurobiol. Exp. (Wars) 2008, 68, 1-9. 
151. Ieraci, A.; Herrera, D.G. Nicotinamide Protects against Ethanol-Induced Apoptotic Neurodegeneration in the Developing Mouse Brain. PLoS Med. 2006, 3, e101.

152. Shen, C.C.; Huang, H.M.; Ou, H.C.; Chen, H.L.; Chen, W.C.; Jeng, K.C. Protective effect of nicotinamide on neuronal cells under oxygen and glucose deprivation and hypoxia/reoxygenation. J. Biomed. Sci. 2004, 11, 472-481.

153. Sonee, M.; Martens, J.R.; Evers, M.R.; Mukherjee, S.K. The effect of tertiary butylhydroperoxide and nicotinamide on human cortical neurons. Neurotoxicology 2003, 24, 443-448.

154. Kiuchi, K.; Kondo, M.; Ueno, S.; Moriguchi, K.; Yoshizawa, K.; Miyake, Y.; Matsumura, M.; Tsubura, A. Functional rescue of $N$-methyl- $N$-nitrosourea-induced retinopathy by nicotinamide in Sprague-Dawley rats. Curr. Eye Res. 2003, 26, 355-362.

155. Reber, F.; Geffarth, R.; Kasper, M.; Reichenbach, A.; Schleicher, E.D.; Siegner, A.; Funk, R.H. Graded sensitiveness of the various retinal neuron populations on the glyoxal-mediated formation of advanced glycation end products and ways of protection. Graefes Arch. Clin. Exp. Ophthalmol. 2003, 241, 213-225.

156. Hoane, M.R.; Gilbert, D.R.; Holland, M.A.; Pierce, J.L. Nicotinamide reduces acute cortical neuronal death and edema in the traumatically injured brain. Neurosci. Lett. 2006, 408, 35-39.

157. Hoane, M.R.; Kaplan, S.A.; Ellis, A.L. The effects of nicotinamide on apoptosis and blood-brain barrier breakdown following traumatic brain injury. Brain Res. 2006, 1125, 185-193.

158. Hoane, M.R.; Pierce, J.L.; Holland, M.A.; Anderson, G.D. Nicotinamide treatment induces behavioral recovery when administered up to 4 hours following cortical contusion injury in the rat. Neuroscience 2008, 154, 861-868.

159. Hoane, M.R.; Pierce, J.L.; Kaufman, N.A.; Beare, J.E. Variation in chronic nicotinamide treatment after traumatic brain injury can alter components of functional recovery independent of histological damage. Oxid. Med. Cell. Longev. 2008, 1, 45-52.

160. Holland, M.A.; Tan, A.A.; Smith, D.C.; Hoane, M.R. Nicotinamide treatment provides acute neuroprotection and GFAP regulation following fluid percussion injury. J. Neurotrauma. 2008, 25, 140-152.

161. Wallis, R.A.; Panizzon, K.L.; Girard, J.M. Traumatic neuroprotection with inhibitors of nitric oxide and ADP- ribosylation. Brain Res. 1996, 710, 169-177.

162. Wang, J.; Zhai, Q.; Chen, Y.; Lin, E.; Gu, W.; McBurney, M.W.; He, Z. A local mechanism mediates NAD-dependent protection of axon degeneration. J. Cell Biol. 2005, 170, 349-355.

163. Yang, J.; Klaidman, L.; Chang, M.; Kem, S.; Sugawara, T.; Chan, P.; Adams, J. Nicotinamide therapy protects against both necrosis and apoptosis in a stroke model. Pharmacol. Biochem. Behav. 2002, 73, 901-910.

164. Gupta, S.; Kaul, C.L.; Sharma, S.S. Neuroprotective effect of combination of poly (ADP-ribose) polymerase inhibitor and antioxidant in middle cerebral artery occlusion induced focal ischemia in rats. Neurol. Res. 2004, 26, 103-107.

165. Sakakibara, Y.; Mitha, A.P.; Ayoub, I.A.; Ogilvy, C.S.; Maynard, K.I. Delayed treatment with nicotinamide (vitamin B3) reduces the infarct volume following focal cerebral ischemia in spontaneously hypertensive rats, diabetic and non-diabetic Fischer 344 rats. Brain Res. 2002, 931, 68-73. 
166. Macleod, M.R.; O'Collins, T.; Howells, D.W.; Donnan, G.A. Pooling of animal experimental data reveals influence of study design and publication bias. Stroke 2004, 35, 1203-1208.

167. Brewer, K.L.; Hardin, J.S. Neuroprotective effects of nicotinamide after experimental spinal cord injury. Acad Emerg. Med. 2004, 11, 125-130.

168. Isbir, C.S.; Ak, K.; Kurtkaya, O.; Zeybek, U.; Akgun, S.; Scheitauer, B.W.; Sav, A.; Cobanoglu, A. Ischemic preconditioning and nicotinamide in spinal cord protection in an experimental model of transient aortic occlusion. Eur. J. Cardiothorac. Surg. 2003, 23, 1028-1033.

169. Anderson, D.W.; Bradbury, K.A.; Schneider, J.S. Broad neuroprotective profile of nicotinamide in different mouse models of MPTP-induced parkinsonism. Eur. J. Neurosci. 2008, 28, 610-617.

170. Williams, A.; Ramsden, D. Nicotinamide: a double edged sword. Parkinsonism. Relat. Disord. 2005, 11, 413-420.

171. Williams, A.C.; Cartwright, L.S.; Ramsden, D.B. Parkinson's disease: the first common neurological disease due to auto-intoxication? QJM 2005, 98, 215-226.

172. Giulumian, A.D.; Meszaros, L.G.; Fuchs, L.C. Endothelin-1-induced contraction of mesenteric small arteries is mediated by ryanodine receptor $\mathrm{Ca} 2+$ channels and cyclic ADP-ribose. $J$. Cardiovasc. Pharmacol. 2000, 36, 758-763.

173. Pietrzak, L.; Mogielnicki, A.; Buczko, W. Nicotinamide and its metabolite Nmethylnicotinamide increase skin vascular permeability in rats. Clin. Exp. Dermatol. 2009, 34, 380-384.

174. Oumouna-Benachour, K.; Hans, C.P.; Suzuki, Y.; Naura, A.; Datta, R.; Belmadani, S.; Fallon, K.; Woods, C.; Boulares, A.H. Poly(ADP-ribose) polymerase inhibition reduces atherosclerotic plaque size and promotes factors of plaque stability in apolipoprotein E-deficient mice: effects on macrophage recruitment, nuclear factor-kappaB nuclear translocation, and foam cell death. Circulation 2007, 115, 2442-2450.

175. Giammona, L.M.; Fuhrken, P.G.; Papoutsakis, E.T.; Miller, W.M. Nicotinamide (vitamin B3) increases the polyploidisation and proplatelet formation of cultured primary human megakaryocytes. Br. J. Haematol. 2006, 135, 554-566.

176. Slominska, E.M.; Yuen, A.; Osman, L.; Gebicki, J.; Yacoub, M.H.; Smolenski, R.T. Cytoprotective effects of nicotinamide derivatives in endothelial cells. Nucleosides Nucleotides Nucleic Acids 2008, 27, 863-866.

177. Sadanaga-Akiyoshi, F.; Yao, H.; Tanuma, S.; Nakahara, T.; Hong, J.S.; Ibayashi, S.; Uchimura, H.; Fujishima, M. Nicotinamide attenuates focal ischemic brain injury in rats: With special reference to changes in nicotinamide and $\mathrm{NAD}+$ levels in ischemic core and penumbra. Neurochem. Res. 2003, 28, 1227-1234.

178. Bowes, J.; Piper, J.; Thiemermann, C. Inhibitors of the activity of poly (ADP-ribose) synthetase reduce the cell death caused by hydrogen peroxide in human cardiac myoblasts. Br. J. Pharmacol. 1998, 124, 1760-1766.

179. Cox, M.J.; Sood, H.S.; Hunt, M.J.; Chandler, D.; Henegar, J.R.; Aru, G.M.; Tyagi, S.C. Apoptosis in the left ventricle of chronic volume overload causes endocardial endothelial dysfunction in rats. Am. J. Physiol. Heart Circ. Physiol. 2002, 282, H1197-1205. 
180. Mateuszuk, L.; Khomich, T.I.; Slominska, E.; Gajda, M.; Wojcik, L.; Lomnicka, M.; Gwozdz, P.; Chlopicki, S. Activation of nicotinamide N-methyltrasferase and increased formation of 1methylnicotinamide (MNA) in atherosclerosis. Pharmacol. Rep. 2009, 61, 76-85.

181. Ito, N.; Bartunek, J.; Spitzer, K.W.; Lorell, B.H. Effects of the nitric oxide donor sodium nitroprusside on intracellular $\mathrm{pH}$ and contraction in hypertrophied myocytes. Circulation 1997, 95, 2303-2311.

182. Gilfillan, A.M.; Rivera, J. The tyrosine kinase network regulating mast cell activation. Immunol. Rev. 2009, 228, 149-169.

183. Ozturk, C.; Ozge, A.; Yalin, O.O.; Yilmaz, I.A.; Delialioglu, N.; Yildiz, C.; Tesdelen, B.; Kudiaki, C. The diagnostic role of serum inflammatory and soluble proteins on dementia subtypes: correlation with cognitive and functional decline. Behav. Neurol. 2007, 18, 207-215.

184. Li, F.; Chong, Z.Z.; Maiese, K. Vital elements of the wnt-frizzled signaling pathway in the nervous system. Curr. Neurovasc. Res. 2005, 2, 331-340.

185. Geijtenbeek, T.B.; Gringhuis, S.I. Signalling through C-type lectin receptors: shaping immune responses. Nat. Rev. Immunol. 2009, 9, 465-479.

186. Salminen, A.; Kaarniranta, K. Siglec receptors and hiding plaques in Alzheimer's disease. J. Mol. Med. 2009, 87, 697-701.

187. Dringen, R. Oxidative and antioxidative potential of brain microglial cells. Antioxid. Redox Signal. 2005, 7, 1223-1233.

188. Maiese, K.; Chong, Z.Z. Insights into oxidative stress and potential novel therapeutic targets for Alzheimer disease. Restor. Neurol. Neurosci. 2004, 22, 87-104.

189. Sankarapandi, S.; Zweier, J.L.; Mukherjee, G.; Quinn, M.T.; Huso, D.L. Measurement and characterization of superoxide generation in microglial cells: evidence for an NADPH oxidasedependent pathway. Arch. Biochem. Biophys. 1998, 353, 312-321.

190. Denes, A.; Ferenczi, S.; Halasz, J.; Kornyei, Z.; Kovacs, K.J. Role of CX3CR1 (fractalkine receptor) in brain damage and inflammation induced by focal cerebral ischemia in mouse. $J$. Cereb. Blood Flow Metab. 2008, 28, 1707-1721.

191. Wu, Y.; Peng, H.; Cui, M.; Whitney, N.P.; Huang, Y.; Zheng, J.C. CXCL12 increases human neural progenitor cell proliferation through Akt-1/FOXO3a signaling pathway. J. Neurochem. 2009, 109, 1157-1167.

192. Bakshi, P.; Margenthaler, E.; Laporte, V.; Crawford, F.; Mullan, M. Novel role of CXCR2 in regulation of gamma-secretase activity. ACS Chem. Biol. 2008, 3, 777-789.

193. Williams, R.; Dhillon, N.K.; Hegde, S.T.; Yao, H.; Peng, F.; Callen, S.; Chebloune, Y.; Davis, R.L.; Buch, S.J. Proinflammatory cytokines and HIV-1 synergistically enhance CXCL10 expression in human astrocytes. Glia 2009, 57, 734-743.

194. Zhao, L.; Ma, W.; Fariss, R.N.; Wong, W.T. Retinal vascular repair and neovascularization are not dependent on CX3CR1 signaling in a model of ischemic retinopathy. Exp. Eye Res. 2009, 88, 1004-1013.

195. Ioka, T.; Tsuruoka, S.; Ito, C.; Iwaguro, H.; Asahara, T.; Fujimura, A.; Kusano, E. Hypertension induced by erythropoietin has a correlation with truncated erythropoietin receptor mRNA in endothelial progenitor cells of hemodialysis patients. Clin. Pharmacol. Ther. 2009, 86, 154-159. 
196. Maiese, K.; Li, F.; Chong, Z.Z. Erythropoietin in the brain: Can the promise to protect be fulfilled? Trends Pharmacol. Sci. 2004, 25, 577-583.

197. Maiese, K.; Li, F.; Chong, Z.Z. Erythropoietin and cancer. JAMA 2005, 293, 1858-1859.

198. Maiese, K.; Chong, Z.Z.; Li, F.; Shang, Y. C. Erythropoietin: Elucidating new cellular targets that broaden therapeutic strategies. Prog. Neurobiol. 2008, 85, 194-213.

199. Maiese, K.; Li, F.; Chong, Z.Z. New avenues of exploration for erythropoietin. JAMA 2005, 293, 90-95.

200. Chen, J.; Connor, K.M.; Aderman, C.M.; Willett, K.L.; Aspegren, O.P.; Smith, L.E. Suppression of retinal neovascularization by erythropoietin siRNA in a mouse model of proliferative retinopathy. Invest. Ophthalmol. Vis. Sci. 2009, 50, 1329-1335.

201. Koh, S.H.; Noh, M.Y.; Cho, G.W.; Kim, K.S.; Kim, S.H. Erythropoietin increases the motility of human bone marrow-multipotent stromal cells (hBM-MSCs) and enhances the production of neurotrophic factors from hBM-MSCs. Stem. Cells Dev. 2009, 18, 411-421.

202. Mori, S.; Sawada, T.; Kubota, K. Asialoerythropoietin is a strong modulator of angiogenesis by bone-marrow cells. J. Invest. Surg. 2007, 20, 357-362.

203. Sathyanarayana, P.; Houde, E.; Marshall, D.; Volk, A.; Makropoulos, D.; Emerson, C.; Pradeep, A.; Bugelski, P.J.; Wojchowski, D.M. CNTO 530 functions as a potent EPO mimetic via unique sustained effects on bone marrow proerythroblast pools. Blood 2009, 113, 4955-4962.

204. Avasarala, J.R.; Konduru, S.S. Recombinant erythropoietin down-regulates IL-6 and CXCR4 genes in TNF-alpha-treated primary cultures of human microvascular endothelial cells: Implications for multiple sclerosis. J. Mol. Neurosci. 2005, 25, 183-189.

205. Ferri, C.; Giuggioli, D.; Sebastiani, M.; Colaci, M. Treatment of severe scleroderma skin ulcers with recombinant human erythropoietin. Clin. Exp. Dermatol. 2007, 32, 287-290.

206. Thorne, M.; Moore, C.S.; Robertson, G.S. Lack of TIMP-1 increases severity of experimental autoimmune encephalomyelitis: Effects of darbepoetin alfa on TIMP-1 null and wild-type mice. J. Neuroimmunol. 2009, 211, 92-100.

207. Cuzzocrea, S.; Mazzon, E.; di Paola, R.; Genovese, T.; Patel, N.S.; Britti, D.; de Majo, M.; Caputi, A.P.; Thiemermann, C. Erythropoietin reduces the degree of arthritis caused by type II collagen in the mouse. Arthritis Rheum. 2005, 52, 940-950.

208. Chong, Z.Z.; Kang, J.Q.; Maiese, K. Apaf-1, Bcl-xL, Cytochrome c, and Caspase-9 Form the Critical Elements for Cerebral Vascular Protection by Erythropoietin. J. Cereb. Blood Flow Metab. 2003, 23, 320-330.

209. Wu, Y.; Shang, Y.; Sun, S.; Liang, H.; Liu, R. Erythropoietin prevents PC12 cells from 1methyl-4-phenylpyridinium ion-induced apoptosis via the Akt/GSK-3beta/caspase-3 mediated signaling pathway. Apoptosis 2007, 12, 1365-1375.

210. Li, F.; Chong, Z.Z.; Maiese, K. Erythropoietin on a Tightrope: Balancing Neuronal and Vascular Protection between Intrinsic and Extrinsic Pathways. Neurosignals 2004, 13, 265-289.

211. Contaldo, C.; Meier, C.; Elsherbiny, A.; Harder, Y.; Trentz, O.; Menger, M.D.; Wanner, G.A. Human recombinant erythropoietin protects the striated muscle microcirculation of the dorsal skinfold from postischemic injury in mice. Am. J. Physiol. Heart Circ. Physiol. 2007, 293, H274-283. 
212. Vairano, M.; Dello Russo, C.; Pozzoli, G.; Battaglia, A.; Scambia, G.; Tringali, G.; Aloe-Spiriti, M. A.; Preziosi, P.; Navarra, P. Erythropoietin exerts anti-apoptotic effects on rat microglial cells in vitro. Eur. J. Neurosci. 2002, 16, 584-592.

213. Andreucci, M.; Fuiano, G.; Presta, P.; Lucisano, G.; Leone, F.; Fuiano, L.; Bisesti, V.; Esposito, P.; Russo, D.; Memoli, B.; Faga, T.; Michael, A. Downregulation of cell survival signalling pathways and increased cell damage in hydrogen peroxide-treated human renal proximal tubular cells by alpha-erythropoietin. Cell Prolif. 2009, 42, 554-561.

214. Kaindl, A.M.; Sifringer, M.; Koppelstaetter, A.; Genz, K.; Loeber, R.; Boerner, C.; Stuwe, J.; Klose, J.; Felderhoff-Mueser, U. Erythropoietin protects the developing brain from hyperoxiainduced cell death and proteome changes. Ann. Neurol. 2008, 64, 523-534.

215. Yis, U.; Kurul, S.H.; Kumral, A.; Tugyan, K.; Cilaker, S.; Yilmaz, O.; Genc, S.; Genc, K. Effect of erythropoietin on oxygen-induced brain injury in the newborn rat. Neurosci. Lett. 2008, 448, 245-249.

216. Chong, Z.Z.; Kang, J.Q.; Maiese, K. Erythropoietin is a novel vascular protectant through activation of Akt1 and mitochondrial modulation of cysteine proteases. Circulation 2002, 106, 2973-2979.

217. Chong, Z.Z.; Kang, J.Q.; Maiese, K. Hematopoietic factor erythropoietin fosters neuroprotection through novel signal transduction cascades. J. Cereb. Blood Flow Metab. 2002, 22, 503-514.

218. Contaldo, C.; Elsherbiny, A.; Lindenblatt, N.; Plock, J.A.; Trentz, O.; Giovanoli, P.; Menger, M.D.; Wanner, G.A. Erythropoietin enhances oxygenation in critically perfused tissue through modulation of nitric oxide synthase. Shock 2009, 31, 599-606.

219. Harder, Y.; Amon, M.; Schramm, R.; Contaldo, C.; Metzkow, E.; Matzen, A.; Rucker, M.; Vollmar, B.; Menger, M.D. Erythropoietin reduces necrosis in critically ischemic myocutaneous tissue by protecting nutritive perfusion in a dose-dependent manner. Surgery 2009, 145, 372-383.

220. Soliz, J.; Thomsen, J.J.; Soulage, C.; Lundby, C.; Gassmann, M. Sex-dependent regulation of hypoxic ventilation in mice and humans is mediated by erythropoietin. Am. J. Physiol. Regul. Integr. Comp. Physiol. 2009, 296, R1837-1846.

221. Bienvenu, A.L.; Ferrandiz, J.; Kaiser, K.; Latour, C.; Picot, S. Artesunate-erythropoietin combination for murine cerebral malaria treatment. Acta Trop. 2008, 106, 104-108.

222. Casals-Pascual, C.; Idro, R.; Picot, S.; Roberts, D.J.; Newton, C.R. Can erythropoietin be used to prevent brain damage in cerebral malaria? Trends Parasitol. 2009, 25, 30-36.

223. Kaiser, K.; Texier, A.; Ferrandiz, J.; Buguet, A.; Meiller, A.; Latour, C.; Peyron, F.; Cespuglio, R.; Picot, S. Recombinant human erythropoietin prevents the death of mice during cerebral malaria. J. Infect. Dis. 2006, 193, 987-995.

224. Yamasaki, M.; Mishima, H.K.; Yamashita, H.; Kashiwagi, K.; Murata, K.; Minamoto, A.; Inaba, T. Neuroprotective effects of erythropoietin on glutamate and nitric oxide toxicity in primary cultured retinal ganglion cells. Brain Res. 2005, 1050, 15-26.

225. Karaca, M.; Odabasoglu, F.; Kumtepe, Y.; Albayrak, A.; Cadirci, E.; Keles, O.N. Protective effects of erythropoietin on ischemia/reperfusion injury of rat ovary. Eur. J. Obstet. Gynecol. Reprod. Biol. 2009, 144, 157-162.

226. Luo, Y.H.; Li, Z.D.; Liu, L.X.; Dong, G.H. Pretreatment with erythropoietin reduces hepatic ischemia-reperfusion injury. Hepatobiliary Pancreat. Dis. Int. 2009, 8, 294-299. 
227. Schmeding, M.; Boas-Knoop, S.; Lippert, S.; Ruehl, M.; Somasundaram, R.; Dagdelen, T.; Neuhaus, P.; Neumann, U.P. Erythropoietin promotes hepatic regeneration after extended liver resection in rats. J. Gastroenterol. Hepatol. 2008, 23, 1125-1131.

228. Schmeding, M.; Hunold, G.; Ariyakhagorn, V.; Rademacher, S.; Boas-Knoop, S.; Lippert, S.; Neuhaus, P.; Neumann, U.P. Erythropoietin reduces ischemia-reperfusion injury after liver transplantation in rats. Transpl. Int. 2009, 738-746.

229. Schmeding, M.; Neumann, U.P.; Boas-Knoop, S.; Spinelli, A.; Neuhaus, P. Erythropoietin reduces ischemia-reperfusion injury in the rat liver. Eur. Surg. Res. 2007, 39, 189-197.

230. Aoshiba, K.; Onizawa, S.; Tsuji, T.; Nagai, A. Therapeutic effects of erythropoietin in murine models of endotoxin shock. Crit. Care Med. 2009, 37, 889-898.

231. Wagner, F.; Baumgart, K.; Simkova, V.; Georgieff, M.; Radermacher, P.; Calzia, E. Year in review 2007: Critical Care - shock. Crit. Care 2008, 12, 227.

232. MacRedmond, R.; Singhera, G.K.; Dorscheid, D.R. Erythropoietin inhibits respiratory epithelial cell apoptosis in a model of acute lung injury. Eur. Respir. J. 2009, 33, 1403-1414.

233. Tascilar, O.; Cakmak, G.K.; Tekin, I.O.; Emre, A.U.; Ucan, B.H.; Bahadir, B.; Acikgoz, S.; Irkorucu, O.; Karakaya, K.; Balbaloglu, H.; Kertis, G.; Ankarali, H.; Comert, M. Protective effects of erythropoietin against acute lung injury in a rat model of acute necrotizing pancreatitis. World. J. Gastroenterol. 2007, 13, 6172-6182.

234. Wu, H.; Dong, G.; Liu, H.; Xu, B.; Li, D.; Jing, H. Erythropoietin attenuates ischemiareperfusion induced lung injury by inhibiting tumor necrosis factor-alpha and matrix metalloproteinase-9 expression. Eur. J. Pharmacol. 2009, 602, 406-412.

235. Chu, K.; Jung, K.H.; Lee, S.T.; Kim, J.H.; Kang, K.M.; Kim, H.K.; Lim, J.S.; Park, H.K.; Kim, M.; Lee, S.K.; Roh, J.K. Erythropoietin reduces epileptogenic processes following status epilepticus. Epilepsia 2008, 49, 1723-1732.

236. Mikati, M.A.; Hokayem, J.A.; Sabban, M.E. Effects of a single dose of erythropoietin on subsequent seizure susceptibility in rats exposed to acute hypoxia at p10. Epilepsia 2007, 48, 175-181.

237. Nadam, J.; Navarro, F.; Sanchez, P.; Moulin, C.; Georges, B.; Laglaine, A.; Pequignot, J.M.; Morales, A.; Ryvlin, P.; Bezin, L. Neuroprotective effects of erythropoietin in the rat hippocampus after pilocarpine-induced status epilepticus. Neurobiol. Dis. 2007, 25, 412-426.

238. Chattopadhyay, M.; Walter, C.; Mata, M.; Fink, D.J. Neuroprotective effect of herpes simplex virus-mediated gene transfer of erythropoietin in hyperglycemic dorsal root ganglion neurons. Brain 2009, 132, 879-888.

239. Chong, Z.Z.; Shang, Y.C.; Maiese, K. Vascular injury during elevated glucose can be mitigated by erythropoietin and Wnt signaling. Curr. Neurovasc. Res. 2007, 4, 194-204.

240. Toba, H.; Sawai, N.; Morishita, M.; Murata, S.; Yoshida, M.; Nakashima, K.; Morita, Y.; Kobara, M.; Nakata, T. Chronic treatment with recombinant human erythropoietin exerts renoprotective effects beyond hematopoiesis in streptozotocin-induced diabetic rat. Eur. J. Pharmacol. 2009, 612, 106-114.

241. Montero, M.; Poulsen, F.R.; Noraberg, J.; Kirkeby, A.; van Beek, J.; Leist, M.; Zimmer, J. Comparison of neuroprotective effects of erythropoietin (EPO) and carbamylerythropoietin 
(CEPO) against ischemia-like oxygen-glucose deprivation (OGD) and NMDA excitotoxicity in mouse hippocampal slice cultures. Exp. Neurol. 2007, 204, 106-117.

242. Yoo, J.Y.; Won, Y.J.; Lee, J.H.; Kim, J.U.; Sung, I.Y.; Hwang, S.J.; Kim, M.J.; Hong, H.N. Neuroprotective effects of erythropoietin posttreatment against kainate-induced excitotoxicity in mixed spinal cultures. J. Neurosci. Res. 2009, 87, 150-163.

243. Miki, T.; Miura, T.; Yano, T.; Takahashi, A.; Sakamoto, J.; Tanno, M.; Kobayashi, H.; Ikeda, Y.; Nishihara, M.; Naitoh, K.; Ohori, K.; Shimamoto, K. Alteration in erythropoietin-induced cardioprotective signaling by postinfarct ventricular remodeling. J. Pharmacol. Exp. Ther. 2006, 317, 68-75.

244. Ma, R.; Xiong, N.; Huang, C.; Tang, Q.; Hu, B.; Xiang, J.; Li, G. Erythropoietin protects PC12 cells from beta-amyloid(25-35)-induced apoptosis via PI3K/Akt signaling pathway. Neuropharmacology 2009, 56, 1027-1034.

245. Sun, Z.K.; Yang, H.Q.; Pan, J.; Zhen, H.; Wang, Z.Q.; Chen, S.D.; Ding, J.Q. Protective effects of erythropoietin on tau phosphorylation induced by beta-amyloid. J. Neurosci. Res. 2008, 86, 3018-3027.

246. Brunner, S.; Winogradow, J.; Huber, B.C.; Zaruba, M.M.; Fischer, R.; David, R.; Assmann, G.; Herbach, N.; Wanke, R.; Mueller-Hoecker, J.; Franz, W.M. Erythropoietin administration after myocardial infarction in mice attenuates ischemic cardiomyopathy associated with enhanced homing of bone marrow-derived progenitor cells via the CXCR-4/SDF-1 axis. FASEB J. 2009, 23, 351-361.

247. Chen, J.; Connor, K.M.; Aderman, C.M.; Smith, L.E. Erythropoietin deficiency decreases vascular stability in mice. J. Clin. Invest. 2008, 118, 526-533.

248. Chong, Z.Z.; Maiese, K. Erythropoietin involves the phosphatidylinositol 3-kinase pathway, 143-3 protein and FOXO3a nuclear trafficking to preserve endothelial cell integrity. $\mathrm{Br}$. $\mathrm{J}$. Pharmacol. 2007, 150, 839-850.

249. Incagnoli, P.; Ramond, A.; Joyeux-Faure, M.; Pepin, J.L.; Levy, P.; Ribuot, C. Erythropoietin improved initial resuscitation and increased survival after cardiac arrest in rats. Resuscitation 2009, 80, 696-700.

250. Ruifrok, W.P.; de Boer, R.A.; Westenbrink, B.D.; van Veldhuisen, D.J.; van Gilst, W.H. Erythropoietin in cardiac disease: new features of an old drug. Eur. J. Pharmacol. 2008, 585, 270-277.

251. Timmer, S.A.; De Boer, K.; Knaapen, P.; Gotte, M.J.; Van Rossum, A.C. The potential role of erythropoietin in chronic heart failure: from the correction of anemia to improved perfusion and reduced apoptosis? J. Card. Fail. 2009, 15, 353-361.

252. Uitterdijk, A.; Groenendijk, B.C.; van Der Giessen, W.J. Stem cell therapy for chronic heart failure. Hellenic. J. Cardiol. 2009, 50, 127-132.

253. Cherian, L.; Goodman, J.C.; Robertson, C. Neuroprotection with erythropoietin administration following controlled cortical impact injury in rats. J. Pharmacol. Exp. Ther. 2007, 322, 789-794.

254. Margulies, S.; Hicks, R.; Combination Therapies for Traumatic Brain Injury Workshop, L. Combination therapies for traumatic brain injury: prospective considerations. J. Neurotrauma. 2009, 26, 925-939.

255. Matis, G.K.; Birbilis, T.A. Erythropoietin in spinal cord injury. Eur. Spine. J. 2009, 18, 314-323. 
256. Verdonck, O.; Lahrech, H.; Francony, G.; Carle, O.; Farion, R.; Van de Looij, Y.; Remy, C.; Segebarth, C.; Payen, J.F. Erythropoietin protects from post-traumatic edema in the rat brain. J. Cereb. Blood Flow Metab. 2007, 27, 1369-1376.

257. Zhong, Y.S.; Liu, X.H.; Cheng, Y.; Min, Y.J. Erythropoietin with retrobulbar administration protects retinal ganglion cells from acute elevated intraocular pressure in rats. J. Ocul. Pharmacol. Ther. 2008, 24, 453-459.

258. Chang, Y.K.; Choi, D.E.; Na, K.R.; Lee, S.J.; Suh, K.S.; Kim, S.Y.; Shin, Y.T.; Lee, K.W. Erythropoietin attenuates renal injury in an experimental model of rat unilateral ureteral obstruction via anti-inflammatory and anti-apoptotic effects. J. Urol. 2009, 181, 1434-1443.

259. Sharples, E.J.; Thiemermann, C.; Yaqoob, M.M. Mechanisms of disease: Cell death in acute renal failure and emerging evidence for a protective role of erythropoietin. Nat. Clin. Pract. Nephrol. 2005, 1, 87-97.

260. Sharples, E.J.; Yaqoob, M.M. Erythropoietin in experimental acute renal failure. Nephron. Exp. Nephrol. 2006, 104, e83-88.

261. Reddy, S.; Young, M.; Ginn, S. Immunoexpression of interleukin-1beta in pancreatic islets of NOD mice during cyclophosphamide-accelerated diabetes: co-localization in macrophages and endocrine cells and its attenuation with oral nicotinamide. Histochem. J. 2001, 33, 317-327.

262. Chen, C.F.; Wang, D.; Hwang, C.P.; Liu, H.W.; Wei, J.; Lee, R.P.; Chen, H.I. The protective effect of niacinamide on ischemia-reperfusion-induced liver injury. J. Biomed. Sci. 2001, 8, 446-452.

263. Moberg, L.; Olsson, A.; Berne, C.; Felldin, M.; Foss, A.; Kallen, R.; Salmela, K.; Tibell, A.; Tufveson, G.; Nilsson, B.; Korsgren, O. Nicotinamide inhibits tissue factor expression in isolated human pancreatic islets: implications for clinical islet transplantation. Transplantation 2003, 76, $1285-1288$.

264. Ungerstedt, J.S.; Blomback, M.; Soderstrom, T. Nicotinamide is a potent inhibitor of proinflammatory cytokines. Clin. Exp. Immunol. 2003, 131, 48-52.

265. Traister, A.; Breitman, I.; Bar-Lev, E.; Zvibel, I.; Harel, A.; Halpern, Z.; Oren, R. Nicotinamide induces apoptosis and reduces collagen I and pro-inflammatory cytokines expression in rat hepatic stellate cells. Scand. J. Gastroenterol. 2005, 40, 1226-1234.

266. Fukuzawa, M.; Satoh, J.; Muto, G.; Muto, Y.; Nishimura, S.; Miyaguchi, S.; Qiang, X.L.; Toyota, T. Inhibitory effect of nicotinamide on in vitro and in vivo production of tumor necrosis factor-alpha. Immunol. Lett. 1997, 59, 7-11.

267. Hiromatsu, Y.; Sato, M.; Yamada, K.; Nonaka, K. Inhibitory effects of nicotinamide on recombinant human interferon- gamma-induced intercellular adhesion molecule-1 (ICAM-1) and HLA-DR antigen expression on cultured human endothelial cells. Immunol. Lett. 1992, 31, 35-39.

268. Kaneko, S.; Wang, J.; Kaneko, M.; Yiu, G.; Hurrell, J.M.; Chitnis, T.; Khoury, S.J.; He, Z. Protecting axonal degeneration by increasing nicotinamide adenine dinucleotide levels in experimental autoimmune encephalomyelitis models. J. Neurosci. 2006, 26, 9794-9804.

269. Kroger, H.; Hauschild, A.; Ohde, M.; Bache, K.; Voigt, W.P.; Ehrlich, W. Enhancing the inhibitory effect of nicotinamide upon collagen II induced arthritis in mice using Nacetylcysteine. Inflammation 1999, 23, 111-115. 
270. Bryniarski, K.; Biedron, R.; Jakubowski, A.; Chlopicki, S.; Marcinkiewicz, J. Anti-inflammatory effect of 1-methylnicotinamide in contact hypersensitivity to oxazolone in mice; involvement of prostacyclin. Eur. J. Pharmacol. 2008, 578, 332-338.

271. Soop, A.; Albert, J.; Weitzberg, E.; Bengtsson, A.; Nilsson, C. G.; Sollevi, A. Nicotinamide does not influence cytokines or exhaled NO in human experimental endotoxaemia. Clin. Exp. Immunol. 2004, 135, 114-118.

272. Chan, J.C.; Malik, V.; Jia, W.; Kadowaki, T.; Yajnik, C.S.; Yoon, K.H.; Hu, F.B. Diabetes in Asia: epidemiology, risk factors, and pathophysiology. JAMA 2009, 301, 2129-2140.

273. Rebecchi, K.R.; Wenke, J.L.; Go, E.P.; Desaire, H. Label-free quantitation: a new glycoproteomics approach. J. Am. Soc. Mass Spectrom. 2009, 20, 1048-1059.

274. McIntyre, R.S.; Rasgon, N.L.; Kemp, D.E.; Nguyen, H.T.; Law, C.W.; Taylor, V.H.; Woldeyohannes, H.O.; Alsuwaidan, M.T.; Soczynska, J.K.; Kim, B.; Lourenco, M.T.; Kahn, L.S.; Goldstein, B.I. Metabolic syndrome and major depressive disorder: co-occurrence and pathophysiologic overlap. Curr. Diab. Rep. 2009, 9, 51-59.

275. Kuhad, A.; Bishnoi, M.; Tiwari, V.; Chopra, K. Suppression of NF-kappabeta signaling pathway by tocotrienol can prevent diabetes associated cognitive deficits. Pharmacol. Biochem. Behav. 2009, 92, 251-259.

276. Donahoe, S.M.; Stewart, G.C.; McCabe, C.H.; Mohanavelu, S.; Murphy, S.A.; Cannon, C.P.; Antman, E.M. Diabetes and mortality following acute coronary syndromes. JAMA 2007, 298, 765-775.

277. Young, G.S.; Jacobson, E.L.; Kirkland, J.B. Water maze performance in young male Long-Evans rats is inversely affected by dietary intakes of niacin and may be linked to levels of the NAD+ metabolite cADPR. J. Nutr. 2007, 137, 1050-1057.

278. Reddy, S.; Bibby, N.J.; Wu, D.; Swinney, C.; Barrow, G.; Elliott, R.B. A combined casein-freenicotinamide diet prevents diabetes in the NOD mouse with minimum insulitis. Diabetes Res. Clin. Pract. 1995, 29, 83-92.

279. Hu, Y.; Wang, Y.; Wang, L.; Zhang, H.; Zhao, B.; Zhang, A.; Li, Y. Effects of nicotinamide on prevention and treatment of streptozotocin-induced diabetes mellitus in rats. Chin. Med. J. (Engl.) 1996, 109, 819-822.

280. Stevens, M.J.; Li, F.; Drel, V.R.; Abatan, O.I.; Kim, H.; Burnett, D.; Larkin, D.; Obrosova, I.G. Nicotinamide reverses neurological and neurovascular deficits in streptozotocin diabetic rats. $J$. Pharmacol. Exp. Ther. 2007, 320, 458-464.

281. Cresto, J.C.; Fabiano de Bruno, L.E.; Cao, G.F.; Pastorale, C.F.; Confalonieri, N.; del Carmen Camberos, M.; Basabe, J.C. The association of acetyl-1-carnitine and nicotinamide remits the experimental diabetes in mice by multiple low-dose streptozotocin. Pancreas 2006, 33, 403-411.

282. Chlopicki, S.; Swies, J.; Mogielnicki, A.; Buczko, W.; Bartus, M.; Lomnicka, M.; Adamus, J.; Gebicki, J. 1-Methylnicotinamide (MNA), a primary metabolite of nicotinamide, exerts antithrombotic activity mediated by a cyclooxygenase-2/prostacyclin pathway. Br. J. Pharmacol. 2007, 152, 230-239.

283. Lee, H.I.; Cho, H.J.; Han, J.A.; Jang, S.Y.; Wang, K.M.; Kang, H.T.; Hwan, E.S. Transient downregulation of protein $\mathrm{O}-\mathrm{N}$-acetylglucosaminylation by treatment of high-dose nicotinamide in human cells. Exp. Mol. Med. 2008, 40, 246-253. 
284. Tam, D.; Tam, M.; Maynard, K.I. Nicotinamide modulates energy utilization and improves functional recovery from ischemia in the in vitro rabbit retina. Ann. N. Y. Acad. Sci. 2005, 1053, 258-268.

285. Olmos, P.R.; Hodgson, M.I.; Maiz, A.; Manrique, M.; De Valdes, M.D.; Foncea, R.; Acosta, A.M.; Emmerich, M.V.; Velasco, S.; Muniz, O.P.; Oyarzun, C.A.; Claro, J.C.; Bastias, M.J.; Toro, L.A. Nicotinamide protected first-phase insulin response (FPIR) and prevented clinical disease in first-degree relatives of type-1 diabetics. Diabetes Res. Clin. Pract. 2006, 71, 320-333.

286. Crino, A.; Schiaffini, R.; Ciampalini, P.; Suraci, M.C.; Manfrini, S.; Visalli, N.; Matteoli, M.C.; Patera, P.; Buzzetti, R.; Guglielmi, C.; Spera, S.; Costanza, F.; Fioriti, E.; Pitocco, D.; Pozzilli, P. A two year observational study of nicotinamide and intensive insulin therapy in patients with recent onset type 1 diabetes mellitus. J. Pediatr. Endocrinol. Metab. 2005, 18, 749-754.

287. Eto, N.; Miyata, Y.; Ohno, H.; Yamashita, T. Nicotinamide prevents the development of hyperphosphataemia by suppressing intestinal sodium-dependent phosphate transporter in rats with adenine-induced renal failure. Nephrol. Dial. Transplant. 2005, 20, 1378-1384.

288. Liu, H.K.; Green, B.D.; Flatt, P.R.; McClenaghan, N.H.; McCluskey, J.T. Effects of long-term exposure to nicotinamide and sodium butyrate on growth, viability, and the function of clonal insulin secreting cells. Endocr. Res. 2004, 30, 61-68.

289. Reddy, S.; Salari-Lak, N.; Sandler, S. Long-term effects of nicotinamide-induced inhibition of poly(adenosine diphosphate-ribose) polymerase activity in rat pancreatic islets exposed to interleukin-1 beta. Endocrinology 1995, 136, 1907-1912.

290. Gaudineau, C.; Auclair, K. Inhibition of human P450 enzymes by nicotinic acid and nicotinamide. Biochem. Biophys. Res. Commun. 2004, 317, 950-956.

291. Magni, G.; Amici, A.; Emanuelli, M.; Orsomando, G.; Raffaelli, N.; Ruggieri, S. Enzymology of NAD+ homeostasis in man. Cell Mol. Life Sci. 2004, 61, 19-34.

292. Lin, S.J.; Guarente, L. Nicotinamide adenine dinucleotide, a metabolic regulator of transcription, longevity and disease. Curr. Opin. Cell Biol. 2003, 15, 241-246.

293. Hageman, G.J.; Stierum, R.H. Niacin, poly(ADP-ribose) polymerase-1 and genomic stability. Mutat. Res. 2001, 475, 45-56.

294. Newsholme, P.; Haber, E.P.; Hirabara, S.M.; Rebelato, E.L.; Procopio, J.; Morgan, D.; OliveiraEmilio, H.C.; Carpinelli, A.R.; Curi, R. Diabetes associated cell stress and dysfunction: role of mitochondrial and non-mitochondrial ROS production and activity. J. Physiol. 2007, 583, 9-24.

295. Di Lisa, F.; Menabo, R.; Canton, M.; Barile, M.; Bernardi, P. Opening of the mitochondrial permeability transition pore causes depletion of mitochondrial and cytosolic NAD + and is a causative event in the death of myocytes in postischemic reperfusion of the heart. J. Biol. Chem. 2001, 276, 2571-2575.

296. Rachek, L.I.; Thornley, N.P.; Grishko, V.I.; LeDoux, S.P.; Wilson, G.L. Protection of INS-1 cells from free fatty acid-induced apoptosis by targeting hOGG1 to mitochondria. Diabetes 2006, 55, 1022-1028.

297. Kelley, D.E.; He, J.; Menshikova, E.V.; Ritov, V.B. Dysfunction of mitochondria in human skeletal muscle in type 2 diabetes. Diabetes 2002, 51, 2944-2950. 
298. Choo, H.J.; Kim, J.H.; Kwon, O.B.; Lee, C.S.; Mun, J.Y.; Han, S.S.; Yoon, Y.S.; Yoon, G.; Choi, K.M.; Ko, Y.G. Mitochondria are impaired in the adipocytes of type 2 diabetic mice. Diabetologia 2006, 49, 784-791.

299. Petersen, K.F.; Befroy, D.; Dufour, S.; Dziura, J.; Ariyan, C.; Rothman, D.L.; DiPietro, L.; Cline, G.W.; Shulman, G.I. Mitochondrial dysfunction in the elderly: Possible role in insulin resistance. Science 2003, 300, 1140-1142.

300. Petersen, K.F.; Dufour, S.; Befroy, D.; Garcia, R.; Shulman, G.I. Impaired mitochondrial activity in the insulin-resistant offspring of patients with type 2 diabetes. N. Engl. J. Med. 2004, 350, 664-671.

301. Schinder, A.F.; Olson, E.C.; Spitzer, N.C.; Montal, M. Mitochondrial dysfunction is a primary event in glutamate neurotoxicity. J. Neurosci. 1996, 16, 6125-6133.

302. Walter, D.H.; Haendeler, J.; Galle, J.; Zeiher, A.M.; Dimmeler, S. Cyclosporin A inhibits apoptosis of human endothelial cells by preventing release of cytochrome $\mathrm{C}$ from mitochondria. Circulation 1998, 98, 1153-1157.

303. Halestrap, A.P.; Woodfield, K.Y.; Connern, C.P. Oxidative stress, thiol reagents, and membrane potential modulate the mitochondrial permeability transition by affecting nucleotide binding to the adenine nucleotide translocase. J. Biol. Chem. 1997, 272, 3346-3354.

304. La Piana, G.; Marzulli, D.; Consalvo, M.I.; Lofrumento, N.E. Cytochrome c-induced cytosolic nicotinamide adenine dinucleotide oxidation, mitochondrial permeability transition, and apoptosis. Arch. Biochem. Biophys. 2003, 410, 201-211.

305. Maiese, K.; Chong, Z.Z.; Shang, Y.C. "Sly as a FOXO": New paths with Forkhead signaling in the brain. Curr. Neurovasc. Res. 2007, 4, 295-302.

306. Maiese, K.; Chong, Z.Z.; Shang, Y. C. OutFOXOing disease and disability: The therapeutic potential of targeting FoxO proteins. Trends Mol. Med. 2008, 14, 219-227.

307. Coffer, P.J. When less is more: the PI3K pathway as a determinant of tumor response to dietary restriction. Cell Res. 2009, 19, 797-799.

308. Jacobsen, E.A.; Ananieva, O.; Brown, M.L.; Chang, Y. Growth, differentiation, and malignant transformation of pre-B cells mediated by inducible activation of $\mathrm{v}$-Abl oncogene. J. Immunol. 2006, 176, 6831-6838.

309. Maiese, K.; Chong, Z.Z.; Shang, Y.C.; Hou, J. Clever cancer strategies with FoxO transcription factors. Cell Cycle 2008, 7, 3829-3839.

310. Maiese, K.; Chong, Z.Z.; Shang, Y.C.; Hou, J. FoxO proteins: cunning concepts and considerations for the cardiovascular system. Clin. Sci. (Lond) 2009, 116, 191-203.

311. Clark, K.L.; Halay, E.D.; Lai, E.; Burley, S.K. Co-crystal structure of the HNF-3/fork head DNA-recognition motif resembles histone H5. Nature 1993, 364, 412-420.

312. Jin, C.; Marsden, I.; Chen, X.; Liao, X. Sequence specific collective motions in a winged helix DNA binding domain detected by $15 \mathrm{~N}$ relaxation NMR. Biochemistry 1998, 37, 6179-6187.

313. Lappas, M.; Lim, R.; Riley, C.; Rice, G.E.; Permezel, M. Localisation and expression of FoxO1 proteins in human gestational tissues. Placenta 2009, 30, 256-262.

314. Chong, Z.Z.; Maiese, K. Targeting WNT, protein kinase B, and mitochondrial membrane integrity to foster cellular survival in the nervous system. Histol. Histopathol. 2004, 19, 495-504. 
315. Kikuchi, A.; Yamamoto, H.; Sato, A. Selective activation mechanisms of Wnt signaling pathways. Trends Cell Biol. 2009, 19, 119-129.

316. Luo, J.M.; Dai, C.F.; Lin, S.Y.; Huang, P.Q. Asymmetric syntheses and Wnt signal inhibitory activity of melleumin A and four analogues of melleumins A and B. Chem. Asian J. 2009, 4, 328-335.

317. Maiese, K.; Li, F.; Chong, Z.Z.; Shang, Y.C. The Wnt signaling pathway: Aging gracefully as a protectionist? Pharmacol. Ther. 2008, 118, 58-81.

318. Muruganandan, S.; Roman, A.A.; Sinal, C.J. Adipocyte differentiation of bone marrow-derived mesenchymal stem cells: cross talk with the osteoblastogenic program. Cell Mol. Life Sci. 2009, 66, 236-253.

319. Slotkin, T.A.; Seidler, F.J.; Fumagalli, F. Targeting of neurotrophic factors, their receptors, and signaling pathways in the developmental neurotoxicity of organophosphates in vivo and in vitro. Brain Res. Bull. 2008, 76, 424-438.

320. Wilusz, M.; Majka, M. Role of the Wnt/beta-catenin network in regulating hematopoiesis. Arch. Immunol. Ther. Exp. (Warsz) 2008, 56, 257-266.

321. Emami, K.H.; Corey, E. When prostate cancer meets bone: control by wnts. Cancer Lett. 2007, 253, 170-179.

322. Espada, J.; Calvo, M.B.; Diaz-Prado, S.; Medina, V. Wnt signalling and cancer stem cells. Clin. Transl. Oncol. 2009, 11, 411-427.

323. Chong, Z.Z.; Li, F.; Maiese, K. Group I Metabotropic Receptor Neuroprotection Requires Akt and Its Substrates that Govern FOXO3a, Bim, and beta-Catenin During Oxidative Stress. Curr. Neurovasc. Res. 2006, 3, 107-117.

324. Zheng, W.H.; Kar, S.; Quirion, R. FKHRL1 and its homologs are new targets of nerve growth factor Trk receptor signaling. J. Neurochem. 2002, 80, 1049-1061.

325. Fei, M.; Lu, M.; Wang, Y.; Zhao, Y.; He, S.; Gao, S.; Ke, Q.; Liu, Y.; Li, P.; Cui, X.; Shen, A.; Cheng, C. Arsenic trioxide-induced growth arrest of human hepatocellular carcinoma cells involving FOXO3a expression and localization. Med. Oncol. 2009, 26, 178-185.

326. Maiese, K.; Hou, J.; Chong, Z.Z.; Shang, Y.C. A fork in the path: Developing therapeutic inroads with FoxO proteins. Oxid. Med. Cell. Longev. 2009, 2, 119-126.

327. Charvet, C.; Alberti, I.; Luciano, F.; Jacquel, A.; Bernard, A.; Auberger, P.; Deckert, M. Proteolytic regulation of Forkhead transcription factor FOXO3a by caspase-3-like proteases. Oncogene 2003, 22, 4557-4568.

328. Tang, B.L.; Chua, C.E. SIRT1 and neuronal diseases. Mol. Aspects Med. 2008, 29, 187-200.

329. Zschoernig, B.; Mahlknecht, U. SIRTUIN 1: regulating the regulator. Biochem. Biophys Res. Commun. 2008, 376, 251-255.

330. Zwaal, R.F.; Schroit, A.J. Pathophysiologic implications of membrane phospholipid asymmetry in blood cells. Blood 1997, 89, 1121-1132.

331. Nemoto, S.; Fergusson, M.M.; Finkel, T. Nutrient availability regulates SIRT1 through a forkhead-dependent pathway. Science 2004, 306, 2105-2108.

332. Ferrara, N.; Rinaldi, B.; Corbi, G.; Conti, V.; Stiuso, P.; Boccuti, S.; Rengo, G.; Rossi, F.; Filippelli, A. Exercise Training Promotes SIRT1 Activity in Aged Rats. Rejuvenation. Res. 2008, $11,139-150$. 
333. Motta, M.C.; Divecha, N.; Lemieux, M.; Kamel, C.; Chen, D.; Gu, W.; Bultsma, Y.; McBurney, M.; Guarente, L. Mammalian SIRT1 represses forkhead transcription factors. Cell 2004, 116, 551-563.

334. Balan, V.; Miller, G.S.; Kaplun, L.; Balan, K.; Chong, Z.Z.; Li, F.; Kaplun, A.; VanBerkum, M.F.; Arking, R.; Freeman, D.C.; Maiese, K.; Tzivion, G. Life span extension and neuronal cell protection by Drosophila nicotinamidase. J. Biol. Chem. 2008, 283, 27810-27819.

335. Chong, Z.Z.; Maiese, K. Enhanced Tolerance against Early and Late Apoptotic Oxidative Stress in Mammalian Neurons through Nicotinamidase and Sirtuin Mediated Pathways. Curr. Neurovasc. Res. 2008, 5, 159-170.

336. Jackson, M.D.; Schmidt, M.T.; Oppenheimer, N.J.; Denu, J.M. Mechanism of nicotinamide inhibition and transglycosidation by Sir2 histone/protein deacetylases. J. Biol. Chem. 2003, 278, 50985-50998.

337. Lee, H.I.; Jang, S.Y.; Kang, H.T.; Hwang, E.S. p53-, SIRT1-, and PARP-1-independent downregulation of p21WAF1 expression in nicotinamide-treated cells. Biochem. Biophys. Res. Commun. 2008, 368, 298-304.

338. Bitterman, K.J.; Anderson, R.M.; Cohen, H.Y.; Latorre-Esteves, M.; Sinclair, D.A. Inhibition of silencing and accelerated aging by nicotinamide, a putative negative regulator of yeast sir2 and human SIRT1. J. Biol. Chem. 2002, 277, 45099-45107.

339. Cai, A.L.; Zipfel, G.J.; Sheline, C.T. Zinc neurotoxicity is dependent on intracellular NAD levels and the sirtuin pathway. Eur. J. Neurosci. 2006, 24, 2169-2176.

340. Porcu, M.; Chiarugi, A. The emerging therapeutic potential of sirtuin-interacting drugs: from cell death to lifespan extension. Trends Pharmacol. Sci. 2005, 26, 94-103.

341. Saunders, L.R.; Verdin, E. Sirtuins: critical regulators at the crossroads between cancer and aging. Oncogene 2007, 26, 5489-5504.

342. Kruszewski, M.; Szumiel, I. Sirtuins (histone deacetylases III) in the cellular response to DNA damage--facts and hypotheses. DNA Repair (Amst) 2005, 4, 1306-1313.

343. Chong, Z.Z.; Li, F.; Maiese, K. Activating Akt and the brain's resources to drive cellular survival and prevent inflammatory injury. Histol. Histopathol. 2005, 20, 299-315.

344. Gayer, C.P.; Chaturvedi, L.S.; Wang, S.; Craig, D.H.; Flanigan, T.; Basson, M.D. Strain-induced proliferation requires the phosphatidylinositol 3-kinase/AKT/glycogen synthase kinase pathway. J. Biol. Chem. 2009, 284, 2001-2011.

345. Anitha, M.; Gondha, C.; Sutliff, R.; Parsadanian, A.; Mwangi, S.; Sitaraman, S.V.; Srinivasan, S. GDNF rescues hyperglycemia-induced diabetic enteric neuropathy through activation of the PI3K/Akt pathway. J. Clin. Invest. 2006, 116, 344-356.

346. An, J.; Zhang, C.; Polavarapu, R.; Zhang, X.; Yepes, M. Tissue-type plasminogen activator and the low-density lipoprotein receptor-related protein induce Akt phosphorylation in the ischemic brain. Blood 2008, 112, 2787-2794.

347. Tsolakidou, A.; Trumbach, D.; Panhuysen, M.; Putz, B.; Deussing, J.; Wurst, W.; Sillaber, I.; Holsboer, F.; Rein, T. Acute stress regulation of neuroplasticity genes in mouse hippocampus CA3 area--possible novel signalling pathways. Mol. Cell Neurosci. 2008, 38, 444-452. 
348. Kim, K.H.; Oudit, G.Y.; Backx, P.H. Erythropoietin protects against doxorubicin-induced cardiomyopathy via a phosphatidylinositol 3-kinase-dependent pathway. J. Pharmacol. Exp. Ther. 2008, 324, 160-169.

349. Tajes, M.; Yeste-Velasco, M.; Zhu, X.; Chou, S.P.; Smith, M.A.; Pallas, M.; Camins, A.; Casadesus, G. Activation of Akt by lithium: Pro-survival pathways in aging. Mech. Ageing. Dev. 2009.

350. Morissette, M.; Al Sweidi, S.; Callier, S.; Di Paolo, T. Estrogen and SERM neuroprotection in animal models of Parkinson's disease. Mol. Cell Endocrinol. 2008, 290, 60-69.

351. Morissette, M.; Le Saux, M.; D'Astous, M.; Jourdain, S.; Al Sweidi, S.; Morin, N.; EstradaCamarena, E.; Mendez, P.; Garcia-Segura, L.M.; Di Paolo, T. Contribution of estrogen receptors alpha and beta to the effects of estradiol in the brain. J. Steroid. Biochem. Mol. Biol. 2008, 108, 327-338.

352. Simak, J.; Holada, K.; Vostal, J.G. Release of annexin V-binding membrane microparticles from cultured human umbilical vein endothelial cells after treatment with camptothecin. BMC Cell Biol. 2002, 3, 11.

353. Li, Y.; Tennekoon, G.I.; Birnbaum, M.; Marchionni, M.A.; Rutkowski, J.L. Neuregulin signaling through a PI3K/Akt/Bad pathway in Schwann cell survival. Mol. Cell. Neurosci. 2001, 17, 761-767.

354. Putcha, G.V.; Deshmukh, M.; Johnson, E.M., Jr. BAX translocation is a critical event in neuronal apoptosis: regulation by neuroprotectants, BCL-2, and caspases. J. Neurosci. 1999, 19, 7476-7485.

355. Yamaguchi, A.; Tamatani, M.; Matsuzaki, H.; Namikawa, K.; Kiyama, H.; Vitek, M.P.; Mitsuda, N.; Tohyama, M. Akt activation protects hippocampal neurons from apoptosis by inhibiting transcriptional activity of p53. J. Biol. Chem. 2001, 276, 5256-5264.

356. Luo, J.; Nikolaev, A.Y.; Imai, S.; Chen, D.; Su, F.; Shiloh, A.; Guarente, L.; Gu, W. Negative control of p53 by Sir2alpha promotes cell survival under stress. Cell 2001, 107, 137-148.

357. Maiese, K.; Chong, Z.Z.; Li, F. Driving cellular plasticity and survival through the signal transduction pathways of metabotropic glutamate receptors. Curr. Neurovasc. Res. 2005, 2, 425-446.

358. Okouchi, M.; Ekshyyan, O.; Maracine, M.; Aw, T.Y. Neuronal apoptosis in neurodegeneration. Antioxid. Redox Signal. 2007, 9, 1059-1096.

359. Engels, I.H.; Stepczynska, A.; Stroh, C.; Lauber, K.; Berg, C.; Schwenzer, R.; Wajant, H.; Janicke, R.U.; Porter, A.G.; Belka, C.; Gregor, M.; Schulze-Osthoff, K.; Wesselborg, S. Caspase8/FLICE functions as an executioner caspase in anticancer drug-induced apoptosis. Oncogene 2000, 19, 4563-4573.

360. Stegh, A.H.; Barnhart, B.C.; Volkland, J.; Algeciras-Schimnich, A.; Ke, N.; Reed, J.C.; Peter, M.E. Inactivation of caspase- 8 on mitochondria of Bcl-xL-expressing MCF7-Fas cells: role for the bifunctional apoptosis regulator protein. J. Biol. Chem. 2002, 277, 4351-4360.

361. Takahashi, H.; Nakamura, S.; Asano, K.; Kinouchi, M.; Ishida-Yamamoto, A.; Iizuka, H. Fas antigen modulates ultraviolet B-induced apoptosis of SVHK cells: sequential activation of caspases 8, 3, and 1 in the apoptotic process. Exp. Cell. Res. 1999, 249, 291-298. 
362. Vanags, D.M.; Porn-Ares, M.I.; Coppola, S.; Burgess, D.H.; Orrenius, S. Protease involvement in fodrin cleavage and phosphatidylserine exposure in apoptosis. J. Biol. Chem. 1996, 271, 31075-31085.

363. Li, P.; Nijhawan, D.; Budihardjo, I.; Srinivasula, S.M.; Ahmad, M.; Alnemri, E.S.; Wang, X. Cytochrome $\mathrm{c}$ and dATP-dependent formation of Apaf-1/caspase-9 complex initiates an apoptotic protease cascade. Cell 1997, 91, 479-489.

364. Whitfield, J.; Neame, S.J.; Paquet, L.; Bernard, O.; Ham, J. Dominant-negative c-Jun promotes neuronal survival by reducing BIM expression and inhibiting mitochondrial cytochrome c release. Neuron 2001, 29, 629-643.

365. Outeiro, T.F.; Grammatopoulos, T.N.; Altmann, S.; Amore, A.; Standaert, D.G.; Hyman, B.T.; Kazantsev, A.G. Pharmacological inhibition of PARP-1 reduces alpha-synuclein- and MPP+induced cytotoxicity in Parkinson's disease in vitro models. Biochem. Biophys. Res. Commun. 2007, 357, 596-602.

366. Satoh, M.S.; Lindahl, T. Role of poly(ADP-ribose) formation in DNA repair. Nature 1992, 356, 356-358.

367. Smets, L.A.; Loesberg, C.; Janssen, M.; Van Rooij, H. Intracellular inhibition of mono(ADPribosylation) by meta- iodobenzylguanidine: specificity, intracellular concentration and effects on glucocorticoid-mediated cell lysis. Biochim. Biophys. Acta 1990, 1054, 49-55.

368. Saldeen, J.; Welsh, N. Nicotinamide-induced apoptosis in insulin producing cells is associated with cleavage of poly(ADP-ribose) polymerase. Mol. Cell. Endocrinol. 1998, 139, 99-107.

369. Uehara, N.; Miki, K.; Tsukamoto, R.; Matsuoka, Y.; Tsubura, A. Nicotinamide blocks N-methyl$N$-nitrosourea-induced photoreceptor cell apoptosis in rats through poly (ADP-ribose) polymerase activity and Jun N-terminal kinase/activator protein-1 pathway inhibition. Exp. Eye Res. 2005, 488-495.

370. Kruman, II; Culmsee, C.; Chan, S.L.; Kruman, Y.; Guo, Z.; Penix, L.; Mattson, M.P. Homocysteine elicits a DNA damage response in neurons that promotes apoptosis and hypersensitivity to excitotoxicity. J. Neurosci. 2000, 20, 6920-6926.

371. Kabra, D.G.; Thiyagarajan, M.; Kaul, C.L.; Sharma, S.S. Neuroprotective effect of 4-amino-1,8napthalimide, a poly(ADP ribose) polymerase inhibitor in middle cerebral artery occlusioninduced focal cerebral ischemia in rat. Brain Res. Bull. 2004, 62, 425-433.

372. Aito, H.; Aalto, K.T.; Raivio, K.O. Adenine nucleotide metabolism and cell fate after oxidant exposure of rat cortical neurons: effects of inhibition of poly(ADP-ribose) polymerase. Brain Res. 2004, 1013, 117-124.

373. Cole, K.; Perez-Polo, J.R. Neuronal trauma model: in search of Thanatos. Int. J. Dev. Neurosci. 2004, 22, 485-496.

374. Thies, R.L.; Autor, A.P. Reactive oxygen injury to cultured pulmonary artery endothelial cells: mediation by poly(ADP-ribose) polymerase activation causing NAD depletion and altered energy balance. Arch. Biochem. Biophys. 1991, 286, 353-363.

375. Tronov, V.A.; Konstantinov, E.M. Hydrogen peroxide-induced DNA repair and death of resting human blood lymphocytes. Biochemistry (Mosc) 2000, 65, 1279-1286. 
376. Kuchmerovska, T.; Shymanskyy, I.; Donchenko, G.; Kuchmerovskyy, M.; Pakirbaieva, L.; Klimenko, A. Poly(ADP-ribosyl)ation enhancement in brain cell nuclei is associated with diabetic neuropathy. J. Diabetes Complicat. 2004, 18, 198-204.

377. Smith, W.W.; Norton, D.D.; Gorospe, M.; Jiang, H.; Nemoto, S.; Holbrook, N.J.; Finkel, T.; Kusiak, J.W. Phosphorylation of p66Shc and forkhead proteins mediates Abeta toxicity. J. Cell Biol. 2005, 169, 331-339.

378. Birkmayer, J.G. Coenzyme nicotinamide adenine dinucleotide: new therapeutic approach for improving dementia of the Alzheimer type. Ann. Clin. Lab. Sci. 1996, 26, 1-9.

379. Morris, M.C.; Evans, D.A.; Bienias, J.L.; Scherr, P.A.; Tangney, C.C.; Hebert, L.E.; Bennett, D.A.; Wilson, R.S.; Aggarwal, N. Dietary niacin and the risk of incident Alzheimer's disease and of cognitive decline. J. Neurol. Neurosurg. Psychiatr. 2004, 75, 1093-1099.

380. Love, S.; Barber, R.; Wilcock, G.K. Increased poly(ADP-ribosyl)ation of nuclear proteins in Alzheimer's disease. Brain 1999, 122 (Pt 2), 247-253.

381. Adamczyk, A.; Czapski, G.A.; Jesko, H.; Strosznajder, R.P. Non Abeta component of Alzheimer's disease amyloid and amyloid beta peptides evoked poly(ADP-ribose) polymerasedependent release of apoptosis-inducing factor from rat brain mitochondria. J. Physiol. Pharmacol. 2005, 56 (Suppl. 2), 5-13.

382. Griffin, R.J.; Ogawa, A.; Williams, B.W.; Song, C.W. Hyperthermic enhancement of tumor radiosensitization strategies. Immunol. Invest. 2005, 34, 343-359.

Sample availability: Not available.

(C) 2009 by the authors; licensee Molecular Diversity Preservation International, Basel, Switzerland. This article is an open-access article distributed under the terms and conditions of the Creative Commons Attribution license (http://creativecommons.org/licenses/by/3.0/). 